\title{
A geothermal application for GOCE satellite gravity data: modelling the crustal heat production and lithospheric temperature field in Central Europe
}

\author{
A. Pastorutti ${ }^{\circledR}$ and C. Braitenberg ${ }^{\circledR}$ \\ Department of Mathematics and Geosciences, University of Trieste, Via Edoardo Weiss 1, 34128 Trieste, Italy. E-mail: alberto.pastorutti@gmail.com
}

Accepted 2019 July 25. Received 2019 July 24; in original form 2019 February 26

\begin{abstract}
S UMMAR Y
Since the completion of the Gravity field and steady-state Ocean Circulation Explorer mission (GOCE), global gravity models of uniform quality and coverage are available. We investigate their potential of being useful tools for estimating the thermal structure of the continental lithosphere, through simulation and real-data test in Central-Eastern Europe across the Trans-European Suture Zone. Heat flow, measured near the Earth surface, is the result of the superposition of a complex set of contributions, one of them being the heat production occurring in the crust. The crust is enriched in radioactive elements respect to the underlying mantle and crustal thickness is an essential parameter in isolating the thermal contribution of the crust. Obtaining reliable estimates of crustal thickness through inversion of GOCEderived gravity models has already proven feasible, especially when weak constraints from other observables are introduced. We test a way to integrate this in a geothermal framework, building a 3-D, steady state, solid Earth conductive heat transport model, from the lithosphereasthenosphere boundary to the surface. This thermal model is coupled with a crust-mantle boundary depth resulting from inverse modelling, after correcting the gravity model for the effects of topography, far-field isostatic roots and sediments. We employ a mixed space- and spectral-domain based forward modelling strategy to ensure full spectral coherency between the limited spectral content of the gravity model and the reductions. Deviations from a direct crustal thickness to crustal heat production relationship are accommodated using a subsequent substitution scheme, constrained by surface heat flow measurements, where available. The result is a 3-D model of the lithosphere characterised in temperature, radiogenic heat and thermal conductivity. It provides added information respect to the lithospheric structure and sparse heat flow measurements alone, revealing a satisfactory coherence with the geological features in the area and their controlling effect on the conductive heat transport.
\end{abstract}

Key words: Composition and structure of the continental crust; Heat flow; Gravity anomalies and Earth structure; Satellite gravity; Heat generation and transport.

\section{INTRODUCTION}

The thermal structure of Earth's interior, the heat transport mechanisms involved and the heat flow observed near its surface are parameters of utmost importance in understanding the phenomena involved in geodynamics and the underlying driving forces. Temperature is also a parameter of direct interest in the exploitation of heat, as a source of geothermal energy or as a critical factor in hydrocarbon system modelling.

Direct measurements are technologically limited to the first kilometres of depth, and carrying them out is a costly task. Therefore, the spatial distribution of samples is uneven and often biased towards areas of anomalously high surface heat flow (Mareschal \&
Jaupart 2013). The collection and maintenance of the publicly available data is an ongoing effort, spanning multiple decades (Lee \& Uyeda 1965).

For these reasons most of the knowledge on the thermal structure of the subsurface relies on the integrated analysis of indirect proxies, such as the petrologic information inferred from xenoliths, data inferred from seismological observables, and other physical or chemical quantities for which a temperature dependence is known (Fischer et al. 2010; Vilà et al. 2010; Afonso et al. 2013).

Satellite-derived gravity models have already shown promising results in integrated geophysical modelling of regional heat flow (Bouman et al. 2015). The resolution and spatial homogeneity of the data obtained by the European Space Agency Gravity 
field and steady-state Ocean Circulation Explorer mission (GOCE, Floberghagen et al. 2011; van der Meijde et al. 2015) suggest that it may be a suitable tool in continental-scale thermal estimates.

While the temperature field in the solid Earth and the measured gravity field are not related by any direct physical law, mass distributions sensed by gravity can be a controlling factor for the temperature distribution at depth. The temperature-density and temperature-velocity relationships provide satisfactory insights in the thermal state of the mantle (Priestley \& McKenzie 2006; Cammarano et al. 2011), but the crust is dominated by the heterogeneous distribution of heat produced by decay of radioactive elements (Jaupart et al. 2016), superimposed with the dynamic effects of transients (i.e. when thermal equilibrium has not yet been reached) and non-conductive heat transfer mechanisms: advection and fluid circulation.

The gravity field anomalies due to variations in crustal thickness are among the largest signals sensed by satellite-borne gravity measurements. The observation error in satellite-only GOCE-based gravity models propagates to a theoretical $0.1 \mathrm{~km}$ uncertainty in Moho determination, ignoring the much larger error contribution due to non-exact density distribution models (Braitenberg et al. 2011).

Therefore, estimating the crustal contribution to the surface heat flow by assuming a 'standard heat production' and scaling it with crustal thickness is tempting. Nevertheless, available evidence suggest against such a simple relationship (Mareschal \& Jaupart 2013). However, crustal thickness variations on their own successfully isolate tectonothermal age groups, terranes and geological provinces. An example of this was shown in Grad et al. (2009), through spatial filtering of their European Plate Moho model at different wavelengths.

Hence, we start with the assumption that in contiguous areas of similar crustal thickness, interpreted as contiguous geological provinces, consistent thermal parameters can be expectedprovided that both the crustal thickness modelling and the thermal analysis are carried out at the same spatial scale. Our fundamental hypothesis is that the 'thermal omission error' due to the unmodelled short-wavelength variability in thermal characteristics should be smaller when this local dependence of heat production on crustal thickness is included.

Keeping a priori information to a reasonable minimum, we assess how a strategy based on crustal thickness inverted from a GOCE-based global gravity model and the available surface heat flow measurements can provide a joint estimate of crustal heat production. Trough interpolation of this heat production estimate we fill in those crustal columns which are devoid of surface heat flow measurements and provide a complete model of temperature at depth - added information that surface heat measurements alone can not provide.

We integrate satellite gravity and direct surface heat flow data with a map of sediment thickness (topography to crystalline basement), as provided by Tesauro et al. (2008) and the depth of the lithosphere-asthenosphere boundary (LAB), as estimated from surface wave inversion by Pasyanos et al. (2014).

The method we are presenting consists of a gravity data reduction and Moho inversion phase, which we describe in Section 2, followed by a thermal modelling and parameter fitting phase, described in Section 3. We have tested the procedure on a study area (Figs 1 and 2) in central-eastern Europe, encompassing different geological contexts and thermal regimes. It is bounded by a box limited by 45 to $55^{\circ} \mathrm{N}, 15$ to $35^{\circ} \mathrm{E}$, transitioning from Phanerozoic lithosphere (Polish-German basin, Carpathians, Pannonian Basin) interested by extension events and orogeny to the Russian platform, crossing the Trans-European Suture Zone (TESZ, Jones et al. 2010). In this area the available estimates of lithospheric thickness range from about $50 \mathrm{~km}$ to values in excess of $250 \mathrm{~km}$ across a steep transition zone, approximately $300 \mathrm{~km}$ wide. This lithospheric geometry is overlaid by a remarkable assortment of crustal features. These conditions result in a wide range of measured surface heat flow values (see Section 3.3), ranging from 16 to $195 \mathrm{~mW} \mathrm{~m}^{-2}$ (mean: $57 \mathrm{~mW} \mathrm{~m}^{-2}$ ). The measurements towards the extremes of this range and short-wavelength variations were attenuated with a spatial-domain filter, since it is expected that they are arising from non-conductive heat transport (e.g. hydrology, shallow melts). The regional grid of filtered surface heat flow measurements so obtained (see Section 5.1) constitutes the dependent variable of our fitting procedure.

\section{GRAVITY MODEL PROCESSING AND INVERSION}

We based the crustal thickness estimation on the solution of a gravity to Moho undulation inverse problem. Its input signal is a reduced gravity disturbance from a global gravity model, which we preprocess by computing and subtracting the contribution of topography, of far-field isostatic effects, and of the basement-to-topography sedimentary overburden. With these reductions we aim at obtaining an anomalous gravity quantity that we interpret as the effect of the varying depth of a crust-to-mantle boundary.

We used the GO_CONS_GCF_2_TIM_r5 release (Pail et al. 2011; Brockmann et al. 2014; GOCE-ESA 2014) of the global gravity model derived from the European Space Agency's Gravity field and steady-state Ocean Circulation Explorer mission (GOCE), providing a ppm-level accuracy for $g$ with a half-wavelength resolution of about $70 \mathrm{~km}$ (Floberghagen et al. 2011). This release comprises both GNSS tracking data-which dominate the gravity field solution up to spherical harmonic degree 30-and observations of the on-board gradiometer, which cover the smaller spatial scales (higher degrees and orders). The harmonic coefficients are obtained from these measurements through a least square regression for full normal equations complete to degree/order 150 for the GNSS and to 280 for the gradiometry. A map of the gravity disturbance in the study area is shown in Fig. 3 A.

\subsection{Reduction for the topographic and isostatic effects}

We applied a global topography correction, computed as gravity disturbance, on a $15^{\prime}$ 'by 15 ' regular grid at $8 \mathrm{~km}$ above the GRS 80 ellipsoid. This was accomplished with the GrafLab software package (Bucha \& Janák 2013) and the spherical harmonics topography effect model dV_ELL_RET2014 by Rexer et al. (2016), based on the EARTH2014 global topography (Hirt \& Rexer 2015). We then subtracted this from the GGM gravity disturbance computed on the same grid. Both the spherical harmonics expansions where evaluated up to degree and order 280. The reduction density for the topography correction was $2670 \mathrm{~kg} \mathrm{~m}^{-3}$ for above-sea-level relief and $1030 \mathrm{~kg} \mathrm{~m}^{-3}$ for oceans.

As shown by Szwillus et al. (2016), the 'global Bouguer anomaly' obtained with this procedure contains a significant longwavelength bias due to the far-field effect of internal masses, including those involved in the isostatic compensation of topography 


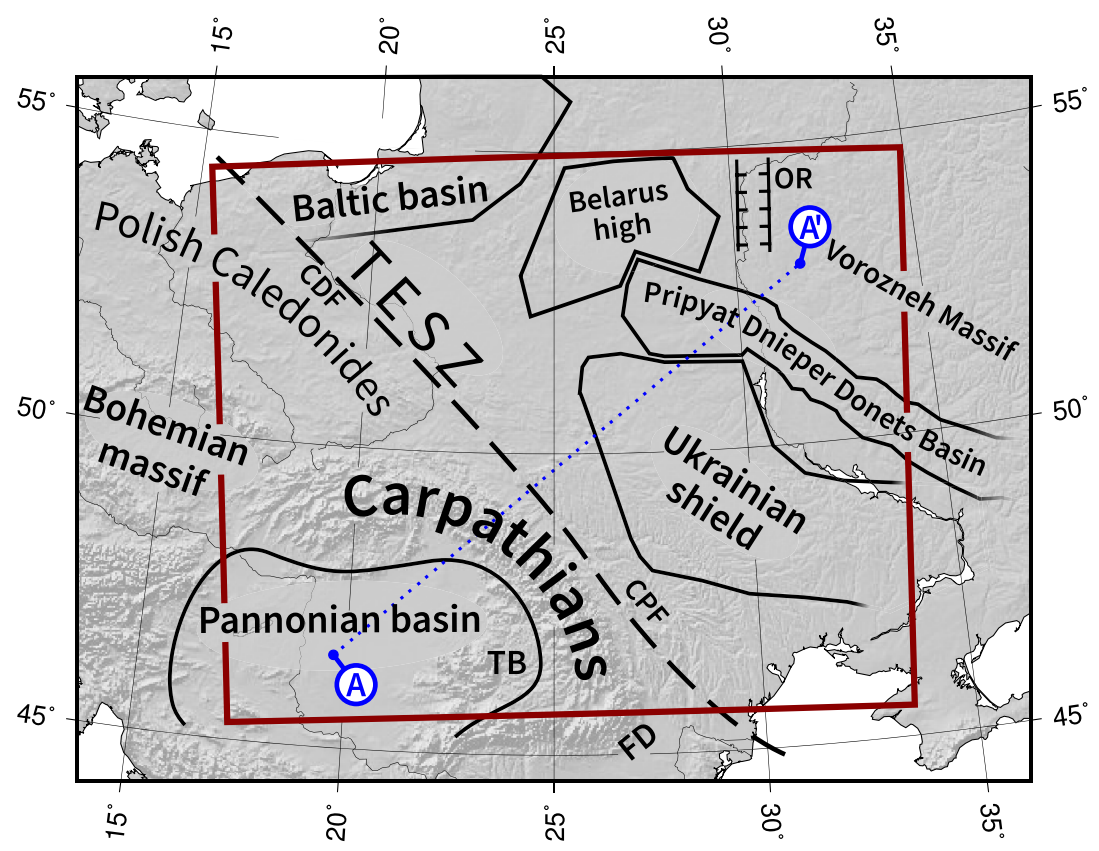

Figure 1. Simplified map of the most significant geological units and boundaries inside the study area and in its proximity. The red rectangle encloses the extents of the Moho inversion result and of the thermal model. TESZ, Trans-European Suture Zone; CDF, Caledonides Foredeep, CPF, Carpathians Foredeep; TB, Transylvania Basin; FD, Focşani Depression; OR, Orsha Rift (Aulacogen). Data redrawn from Tărăpoancă et al. (2003), Tesauro et al. (2008), Artemieva \& Thybo (2013), Mazur et al. (2016) and Starostenko et al. (2018). Profile AA' refers to the section shown in Fig. 17.

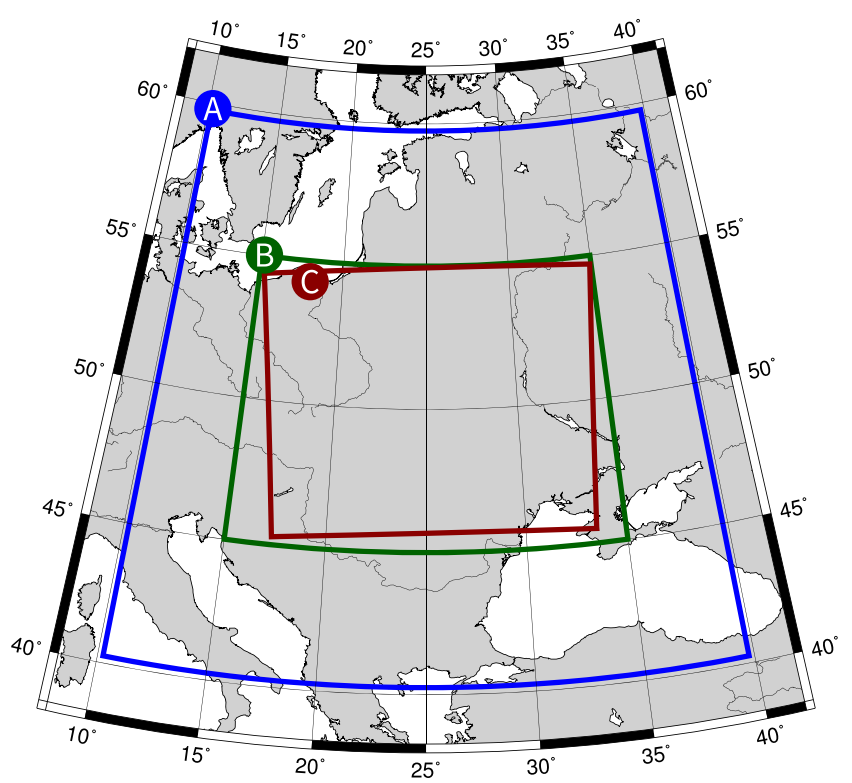

Figure 2. Extents of the modelled areas. (A) area outside of which the far-field gravity effect of crustal root (isostatic effect) was modelled. (B) computation area for the gravity signal and reductions. (C) extents of the inversion results and thermal model (UTM $35 \mathrm{~N}$ grid).

(called isostatic effect). This is different from what would be obtained when processing local gravity data, using the 'classic topographic reduction' computed inside a $167 \mathrm{~km}$ radius (Hayford \& Bowie 1912).

We adopted one of the strategies suggested in Szwillus et al. (2016): accounting for the isostatic effect from masses outside of the study area. We have chosen the LITHO1.0 model (Pasyanos et al. 2014) as a global reference crustal root model. By querying the 'access_litho' program point-wise on a global regular
0.125 by 0.125 degree grid, we extracted the crust-mantle boundary depth ('CRUST3' layer), its density and $V_{P}$ in the lithospheric mantle ('LID' layer).

This procedure provided outlier values on some nodes. We removed the values of crustal density and $V_{P}$ in the lithospheric mantle outside the range defined by three standard deviations around the mean (i.e. $\bar{x} \pm 1.5 \sigma$, with $\bar{x}$ mean value). This implied keeping only the values of crustal density between 2500 and $3300 \mathrm{~kg} \mathrm{~m}^{-3}$ and of lithospheric mantle $V_{P}$ between 7500 and $8800 \mathrm{~m} \mathrm{~s}^{-1}$. Crustal depths of less than zero or more than $80 \mathrm{~km}$ where also considered obvious interpolation artefacts, and removed.

We also compared each node value with a $1.5^{\circ}$ by $1.5^{\circ}$ moving average (12 by 12 grid nodes). We deleted the values with over $10 \mathrm{~km}, 200 \mathrm{~kg} \mathrm{~m}^{-3}$ and $100 \mathrm{~m} \mathrm{~s}^{-1}$ of absolute difference with the local moving average of depth, density and $V_{P}$, respectively. These criteria removed the $2.5 \%$ of the points sampled from LITHO1.0: 10198 points on a 1441 by 2881 global grid. Linear interpolation was used to fill in the removed nodes.

This data set was then low-pass filtered through convolution with a Gaussian kernel with a cut-off wavelength of $4^{\circ}$, that is the wavelength at which the filter response value is $\exp (-0.5)$. This equals to a 0.5 filter response at $3.4^{\circ}$. This was applied as an anti-aliasing filter, prior to downsampling the depth and density data to a 0.5 by 0.5 grid. With these three steps (oversampling, outlier processing, and low-pass filtering) of the data extracted from LITHO1.0 we aimed at removing any artefacts that may arise due to regridding on a rectangular longitude-latitude grid. Since our target is computing and removing a low degree effect, we consider such a drastic smoothing of input data justified.

We then blanked out the grid over a 'study area' defined by $40^{\circ}$ to $60^{\circ}$ latitude, $10^{\circ}$ to $40^{\circ}$ longitude. This area and subsequent crops, which we applied due to edge effects or reprojections, is shown in Fig. 2. 

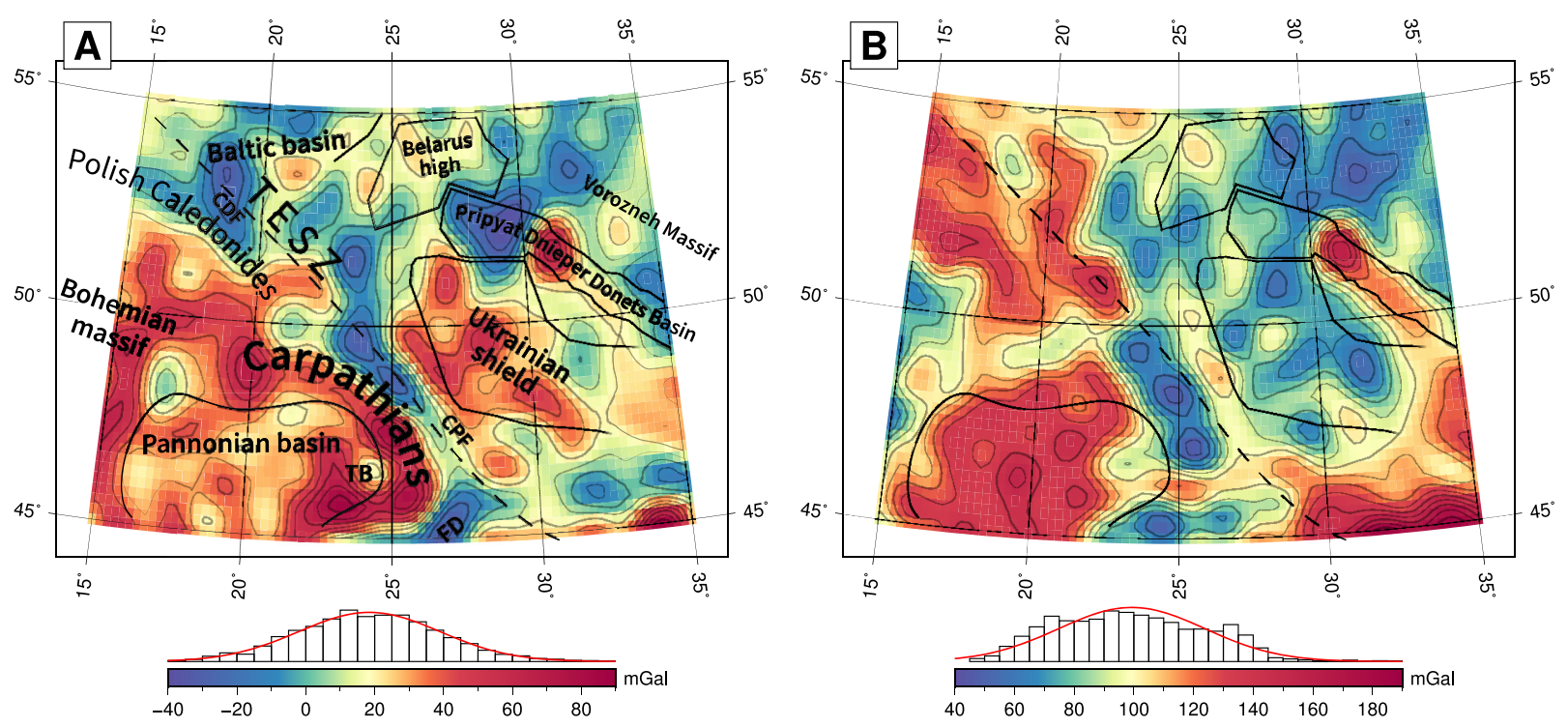

Figure 3. Input and processed gravity data. (A) Gravity disturbance, computed from the global gravity model GO_CONS_GCF_2_TIM_r5, at 8 km over GRS80. (B) Sediment-reduced Bouguer anomaly, obtained by subtracting the topography, isostatic and sediment reductions from the GGM gravity disturbance. Grid cells are shown on a $15^{\prime}$ by $15^{\prime}$ grid, without interpolation. Units are in $\mathrm{mGal}\left(1 \mathrm{mGal}=10^{-5} \mathrm{~m} \mathrm{~s}^{2}\right)$.

This crustal root model was then discretised into 0.5 by 0.5 arcdeg wide spherical tesseroids (Uieda et al. 2016), centred on the same sampling grid. Each tesseroid density is equal to the contrast between the density of the lower crust and of the lithospheric mantle, against a reference Moho at $-35 \mathrm{~km}$. For each grid node, this equals to:

$$
\Delta \rho= \begin{cases}\rho_{C}-\rho_{M} & \text { if } D<\bar{D} \\ \rho_{M}-\rho_{C} & \text { if } D>\bar{D}\end{cases}
$$

with $D$ Moho depth, positive upwards, $\bar{D}$ reference depth and $\rho_{C}$ crustal density as directly extracted from the model. $\rho_{M}$, the mantle density, is provided constant at $3300 \mathrm{~kg} \mathrm{~m}^{-3}$ in LITHO1.0 (Pasyanos et al. 2014), although lateral variations in mantle velocity are provided. We therefore follow the approach used by Sebera et al. (2018), applying the linear density $-V_{P}$ relation by Yegorova \& Pavlenkova (2015), which is based on ACY400 (Montagner \& Anderson 1989):

$\rho_{M}=0.316 V_{P}+769$

with $V_{P}$ in $\mathrm{m} \mathrm{s}^{-1}$ and $\rho$ in $\mathrm{kg} \mathrm{m}^{-3}$.

This yields an average contrast of $380 \mathrm{~kg} \mathrm{~m}^{-3}$, which we note is lower than the global estimates of $485 \mathrm{~kg} \mathrm{~m}^{-3}$ by Tenzer et al. (2012) and of $448 \pm 187 \mathrm{~kg} \mathrm{~m}^{-3}$ by Sjöberg \& Bagherbandi (2011). A globally uniform linear velocity-to-density conversion is a simplified model, which disregards the concurring effects of temperature, pressure and composition. Nevertheless, we deemed it suitable to model a far-field, very long wavelength effect, which would be difficult to estimate otherwise (for a different approach, based on topography and the Airy-Heiskanen isostatic model, see Grombein et al. 2016). Small scale variations are expected to be significantly smoothed out, while still obtaining a more refined and observationbased estimate than the one that would result from a high-pass filter on the gravity model (e.g. by setting the low degree and order coefficients to zero, up to an arbitrary cut off degree).

The gravity effect was computed through space-domain integration, using the Tesseroids program, version 1.2.1 (Uieda et al. 2016; Uieda 2017). We computed the gravity field on a spherical grid, on a radius equal to the semi-major axis of the GRS80 ellipsoid. This field was then filtered and synthesised on the working grid according to the procedure described in Section 2.3. The result is shown in Fig. 4(B).

\subsection{Reduction for the sediment layer effect}

The low-density infill of sedimentary basins results in a negative bias of the Bouguer anomaly, since the topographic effect correction relies on the commonly used $2670 \mathrm{~kg} \mathrm{~m}^{-3}$ crustal reference density (Hinze 2003). Since a negative density contrast is expected at the Moho, not accounting for this bias would result in an overestimation of the crustal thickness. We thus applied a sediment stripping correction (Chen et al. 2014) to the gravity data, using the sediment thickness map provided in Tesauro et al. (2008) in the study area (Fig. 4C) and the rest of the European platform. The rest of the Earth is covered by the sediment thickness data included in LITHO1.0 by Pasyanos et al. (2014). Using a global coverage enabled a realistic estimate of larger wavelengths.

The decrease in porosity (i.e. the volumetric ratio between grains and voids) due to compaction is modelled with the exponential model of Woodside \& Messmer (1961):

$\phi(z)=\phi_{0} \mathrm{e}^{-z / p}$

Where $z$ is depth (positive downwards), $\phi_{0}$ the porosity at the surface and $p$ a characteristic skin-depth, such as $\phi(p)=\phi_{0} \cdot \mathrm{e}^{-1}$. Density can thus be computed with a porosity-weighted sum:

$\rho_{\text {sed }}(z)=[1-\phi(z)] \rho_{G}+\phi(z) \rho_{W}$

Where $\rho_{G}$ and $\rho_{W}$ represent the density of the grain matrix and of water filling the voids, respectively.

This reduction is critically dependent on two quantities: the estimates on the sedimentary cover thickness, and the spatial distribution of density in it. Geological heterogeneities (e.g. lithology, 

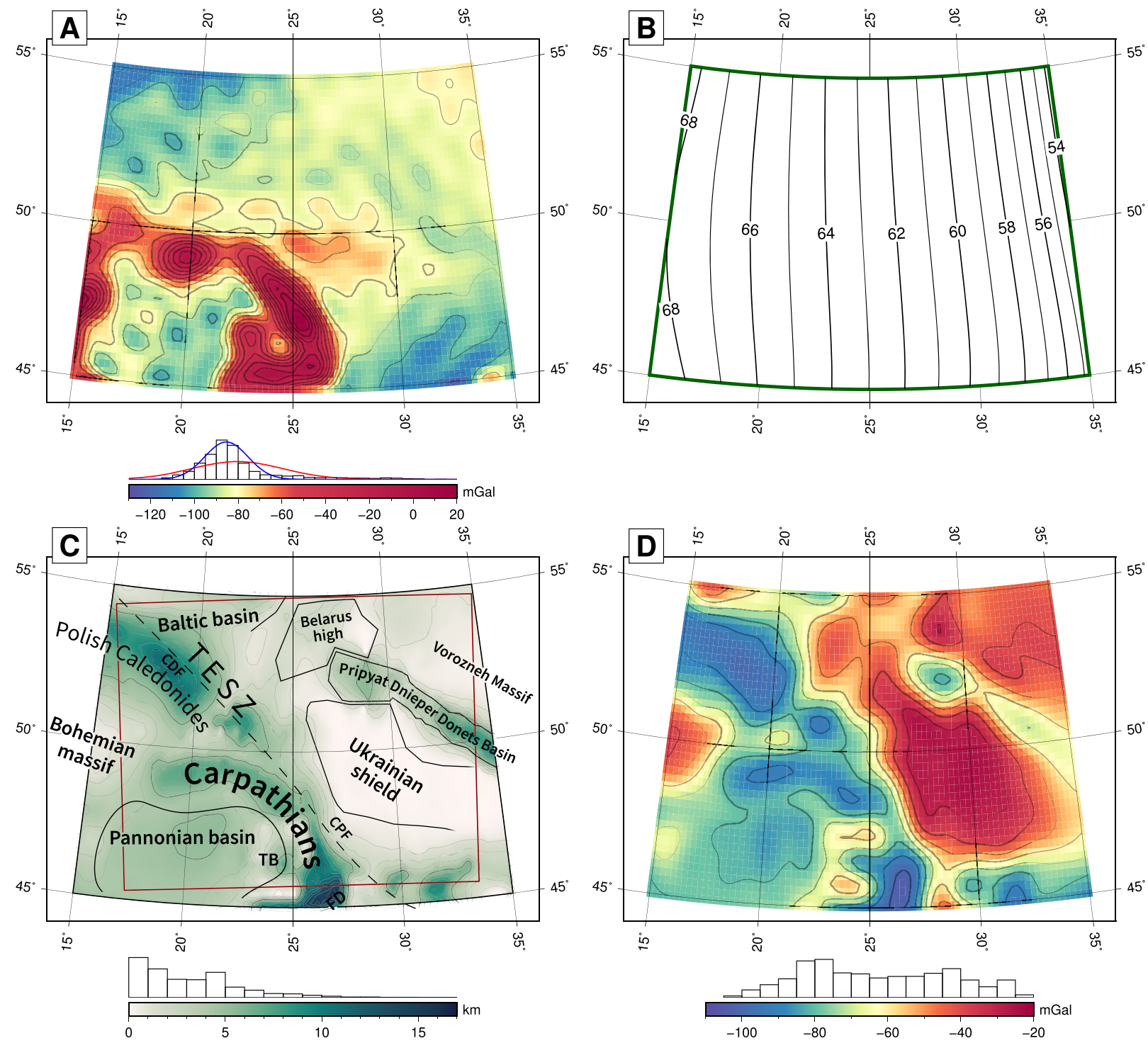

Figure 4. Data reductions to the gravity model. (A) Topographic effect (gravity disturbance) from the RET2014 model (Rexer et al. 2016). A median-centred normal fit is also plotted, in blue. (B) Forward-modelled far field gravity signal (radial component) due to isostatic compensation outside the study area. (C) Sediments thickness $(\mathrm{km})$ in the study area, from Tesauro et al. (2008). Red rectangle: inversion results coverage. Geologic lineaments: see caption of Fig. 1. (D) Sedimentary layer effect. Thicker sedimentary covers result in more negative values. Grid cells are shown on a $15^{\prime}$ by $15^{\prime}$ grid, without interpolation.

basin history, cementation) result in deviations from general depthcompaction laws (Allen \& Allen 2013), hindering the reliability of universal trends.

We computed our sediment effect estimate using the following values: $\rho_{G}=2670 \mathrm{~kg} \mathrm{~m}^{-3}, \rho_{W}=1030 \mathrm{~kg} \mathrm{~m}^{-3}$ (brine), $\phi_{0}=$ $0.5, p=4 \mathrm{~km}\left(1 / p=0.25 \mathrm{~km}^{-1}\right)$. Our depth-density curve lies between the one provided for the Pannonian Basin by Kaban et al. (2010) $\left(\phi_{0}=0.4, p=2.375 \mathrm{~km}\right)$, and the compaction behaviour of shaly sandstones provided in (Allen \& Allen 2013) $\left(\phi_{0}=0.56, p=\right.$ $2.5 \mathrm{~km}$ ).

This contribution was forward modelled with the same method used for the isostatic effect, through integration of discrete tesseroids. We modelled the depth-wise density variation by dividing each tesseroid radially, with a step coarsening with depth (from $50 \mathrm{~m}$ at the surface to $200 \mathrm{~m}$ at $8 \mathrm{~km}$ of depth and more).
Each tesseroid density is equal to the contrast against a $2670 \mathrm{~kg} \mathrm{~m}^{-3}$ reference crustal density. The result is shown in Fig. 4(D).

\subsection{Spectral-domain filtering of the computed reductions}

Subtracting the aforementioned reductions from a band-limited global gravity model carries the risk of introducing spectrally inconsistent higher degree components. This is a consequence of adopting a space-domain forward modelling technique, which generates a band-unlimited gravity signal (Hirt \& Kuhn 2014). To remove any high-order component from the reductions, we carried out the following filtering procedure: (1) first, every reduction signal was computed out globally, in terms of gravity field, on a spherical global grid of radius equal to GRS80 semi-major axis. This grid was an 
equally spaced grid $(N \times 2 N)$ compliant to Driscoll \& Healy (1994) sampling theorem. (2) Then, we expanded it to a spherical harmonic expansion using SHTOOLS by Wieczorek et al. (2018). (3) Using the same software, we synthesised the radial component of gravity from the spherical harmonics coefficients of the field. The SH series was truncated at maximum degree and order 280, and the values were calculated on an ellipsoidal surface, $8 \mathrm{~km}$ above GRS80. This grid extends only over the study area.

\subsection{Inverse modelling}

We inverted for the crust-mantle interface (CMI) with the iterative constrained inverse modelling routine included in the Lithoflex software (Braitenberg et al. 2007), a method that has been extensively tested in similar schemes (Ebbing et al. 2001; Mariani et al. 2013). Its algorithm alternates direct forward modelling and downward continuation, and has some analogies with the strategy of Oldenburg (1974).

This procedure works in planar coordinates, therefore the obtained gravity signal was projected to a local coordinate reference system (WGS84 UTM zone $35 \mathrm{~N}$ ) on a 10 by $10 \mathrm{~km}$ grid. The horizontal spatial resolution for the maximum degree $(N=280)$ of the spherical harmonics expansion of the gravity model, defined as half of the minimum resolved wavelength, is about $71 \mathrm{~km}$. This comes from the $\lambda_{\min } \approx 40000 \mathrm{~km} / N$ rule (Hofmann-Wellenhof \& Moritz 2006). Therefore, the projected grid is oversampled with a factor of 7.1 with respect to the spatial resolution of the GGM.

The inversion parameters are $D$, the reference depth of the undulating interface, $P_{\min }$, the minimum period of the raised cosine low-pass filter applied on the crustal root estimate, and $\Delta \rho$, the density contrast at the interface. The first two parameters are uniform over all the input grid, while $\Delta \rho$ can vary horizontally.

$P_{\min }$ is required for inversion stability and to attenuate any sharp Moho undulation that may result from inverting localised maxima and minima. A value of $160 \mathrm{~km}$ was chosen to filter out shortwavelength Moho geometries which would be spectrally inconsistent with the resolving power of the gravity model. $D$ and $\Delta \rho$ are not estimated by the inversion itself and require integration with external constraints. We extracted them from the global LITHO1.0 model (Pasyanos et al. 2014), adopting the average Moho depth in the study area $(43.9 \mathrm{~km})$ as $D$ and a $4^{\circ}$ low-pass filtered Moho contrast, as computed in Section 2.1. The density contrast map is shown in the right map of Fig. 5. Density is a temperature dependent parameter, due to the effect of thermal expansion (Allen \& Allen 2013). Since our strategy includes the temperature distribution in the lithosphere among the outputs, we could update the density model accordingly (using a thermal expansion model) and recompute the Moho depth estimate, iteratively. This has been tested for, resulting in local variations of up to $3.4 \mathrm{~km}$, with a standard variation of $0.75 \mathrm{~km}$ after one iteration (see Section 4 of the Supporting Information). Owing to the much larger uncertainties in Moho estimates ( \pm 5 to \pm 15 percent, see Grad et al. 2009) and the additional parameter uncertainties involved, we opted to omit the thermal effect on density.

The use of a regional average Moho depth, different from the global reference depth of $35 \mathrm{~km}$ (that we adopted to compute the global isostatic effect), is justified by the fact that we then subtracted the average gravity value over the area, before inversion. Therefore, that average-free gravity anomaly is interpreted as deviations of the crust-mantle interface from the regional average depth.

\section{THERMAL MODELLING}

Our modelling is based on the assumption of steady state, 3-D heat conduction from the thermal-LAB to surface, on which the radioactive heat production is superimposed.

Both heat production and thermal conductivity are non uniform in the domain. This means solving the heat equation for a inhomogeneous media, in the following vector form:

$\nabla \cdot(k(\mathbf{x}) \nabla T(\mathbf{x}))=-A(\mathbf{x})$

With $k$ thermal conductivity (isotropic), $T$ temperature, $A$ heat production per unit of volume, and $\vec{x}$ position vector. We solve eq. (5) with a finite difference scheme on a rectilinear 3-D domain, implemented in Matlab. We adopt a planar approximation, which we deem suitable due to the small radial extent of the model (from the Earth surface to a depth of up to $205 \mathrm{~km}$ ) in respect to its tangential extent (less than 10 by 20 arcdeg, latitude by longitude). Node spacing along the depth axis is non-uniform, to allow for a coarser resolution at higher depths. A zero flux Neumann boundary condition (Smith 1985) is imposed along the vertical sides of the domain.

Upper and bottom boundaries are Dirichlet conditions (Smith 1985), which we set to $15^{\circ} \mathrm{C}$ (surface temperature) and $1200{ }^{\circ} \mathrm{C}$ (LAB temperature, see Section 3.3.2), respectively. To accommodate for a non-flat morphology of these two boundaries, the Jacobian matrix coefficients of all nodes above topography or below the LAB are set to identities (i.e. the temperature of those nodes is fixed). The solver input consists of the grid definition, the $\mathbf{k}$ and $\mathbf{A}$ arrays, and boundary conditions. The finite difference system of linear equations is solved with Matlab built-in Cholesky decomposition for sparse arrays (Davis 2006).

\subsection{Thermal conductivity model}

We adopt a reference thermal conductivity model of sediments, upper and lower crystalline crust and Sub-Continental Lithospheric Mantle (SCLM). It includes standard values, at surface conditions, and models of their dependency on temperature and pressure. Conductivity overall is strongly controlled by lithological properties such as mineralogy, porosity, free and bound water content (Schön 2011; Allen \& Allen 2013). These properties in turn are highly variable parameters, due to the large crustal heterogeneity. This $a$ priori reference may not describe the exact distribution of parameters in each of our model column. It also should not be interpreted as a 'mean model' of thermal conductivity in the study area, since it samples a local geological setting that is realistically expected to be significantly skewed in respect to a global average. Nevertheless, it provides a reference, not unlike reference models used in seismic tomography-deviations from it can be expressed as anomalies and it provides a consistent benchmark to perform comparison with other strategies. The parameters and describing laws are summarised in Table 3. They are described in the next sections.

\subsubsection{Sediments}

The thermal conductivity in the sedimentary layer follows the same exponential compaction model adopted for the sediment reduction to the gravity signal (eq. 3). Therefore, the bulk sediment conductivity can be modelled as a porosity-weighted sum of the conductivities of the rock matrix (grains, $\left.k_{g r}\right)$ and the pore-filling fluid $\left(k_{p f}\right)$ 

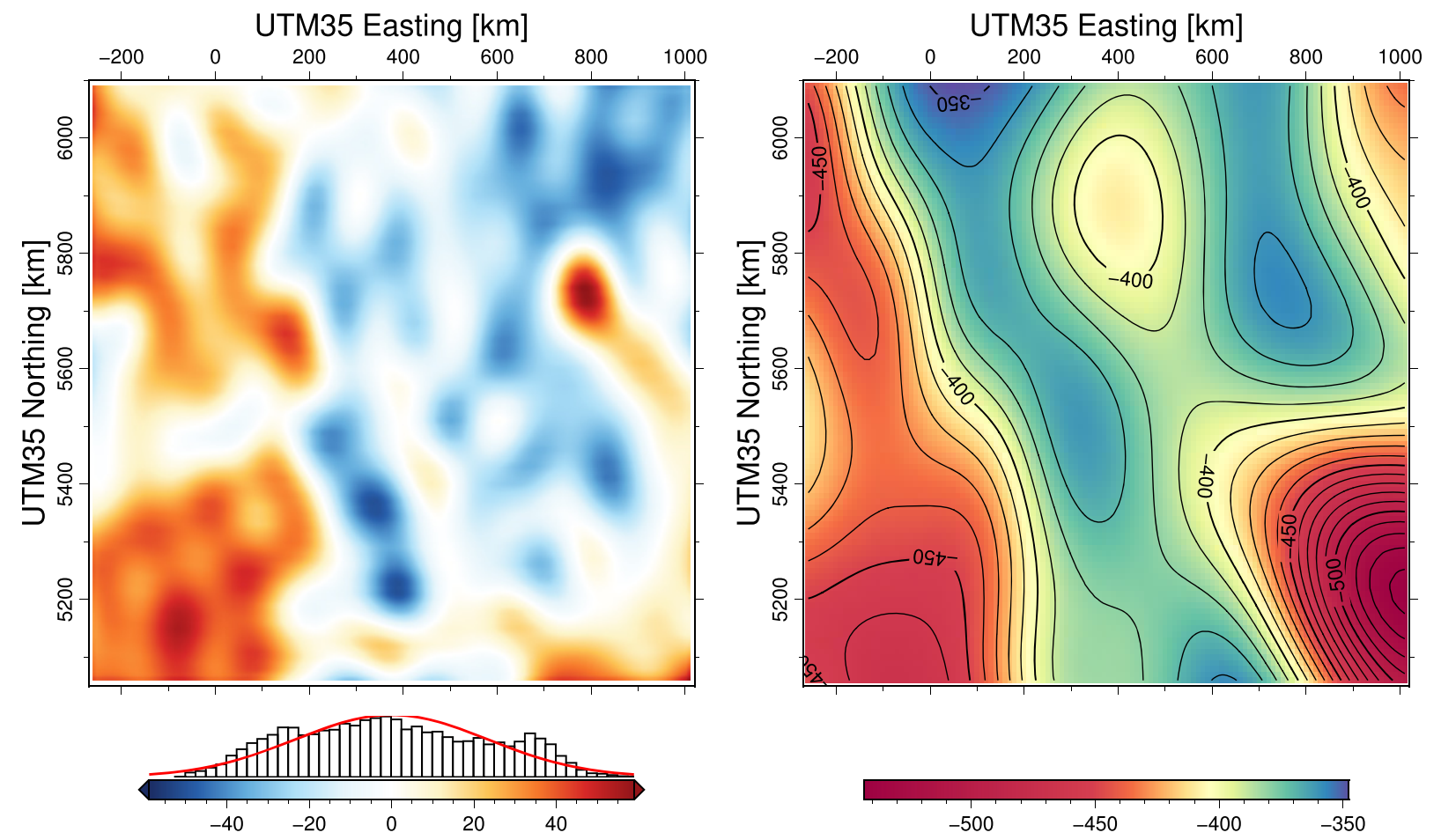

Figure 5. Inversion input, projected to a 10 by $10 \mathrm{~km}$ UTM35N grid. Left-hand panel: inversion input gravity signal, in mGal. Right-hand panel: Moho density contrast $\left(\mathrm{kg} \mathrm{m}^{-3}\right)$ used in inversion, derived from LITHO1.0 (Pasyanos et al. 2014) and the linear $V_{P}$ to SCLM density relationship by Yegorova \& Pavlenkova (2015).

(Woodside \& Messmer 1961; Allen \& Allen 2013):

$k_{\text {sed }}(z)=[1-\phi(z)] k_{g r}+\phi(z) k_{p f}$

The porosity-depth compaction curve is the same used for the gravity modelling. We adopt a thermal conductivity of the solid matrix $\left(k_{g r}\right)$ and of the pore fluid ( $k_{p f}$, assumed brine) equal to 3.0 and $0.6 \mathrm{~W} \mathrm{~m}^{-1} \mathrm{~K}^{-1}$, respectively (Revil 2000).

\subsubsection{Crystalline crust}

We model the inverse dependence between temperature and thermal conductivity in the crystalline continental crust with the empirical relationships proposed by Chapman (1986):

$k(T, z)=k_{0}(1+c z) /(1+b T)$,

where $k_{0}$ is the measured conductivity at surface standard conditions (273.15 $\mathrm{K}$ and $10^{5} \mathrm{~Pa}$ ), and $c$ and $b$ are two parameters expressing the dependency on depth and pressure, respectively.

\subsubsection{Subcontinental lithospheric mantle}

Owing to the higher temperatures reached in the SCLM, the effect of heat transfer by means of black body radiation cannot be overseen. Along with the scarceness of direct samples (i.e. mantle xenoliths), this makes the estimation of thermal conductivity in the SCLM a difficult task, requiring a refined modelling of the behaviour of the lattice of each mineral phase under mantle conditions (Hofmeister 1999). While there is consensus on the reliability of the relationship between the tectonothermal age of the crust and the composition of the underlying lithospheric mantle (Afonso et al. 2008; Griffin et al. 2009), estimating the mineral assemblage given the pressure and temperature conditions requires an adequate thermodynamic modelling (e.g Guerri et al. 2015), which is outside the scope of this work.

We thus assume a reference SCLM, defined by its thermal conductivity at surface conditions and a model of its temperature and pressure dependency. Thermal conductivity at depth is influenced by the superposition of a lattice effect-directly proportional to pressure and inversely proportional to temperature - and a radiative contribution-directly proportional to temperature, that is $k=$ $k_{\text {lat }}(P, T)+k_{\text {rad }}(T)$. We adopt the lattice thermal conductivity $\left(k_{\text {lat }}\right)$ model by Xu et al. (2004), using the values provided for Olivine in the 4-10 $\mathrm{GPa}$ range:

$k_{\text {lat }}=k_{298}\left(\frac{298}{T}\right)^{n}(1+a P)$

where $T$ is temperature in $\mathrm{K}, k_{298}$ the lattice conductivity at $298 \mathrm{~K}$ $\left(4.13 \mathrm{Wm}^{-1} \mathrm{~K}^{-1}\right), n$ an empirical fitting factor $(0.5), a$ the pressure dependency factor $\left(0.032 \mathrm{GPa}^{-1}\right)$ and $P$ pressure in $\mathrm{GPa}$. We computed $P$ as a purely lithostatic pressure, by utilising the same sediment model used in the gravity reduction, a reference crust density of $2670 \mathrm{~kg} \mathrm{~m}^{-3}$, and the same lithospheric mantle density that we calculated in eq. (2).

We account for the radiative component $\left(k_{\text {rad }}\right)$ by adopting the model of Hasterok \& Chapman (2011):

$k_{\text {rad }}=\frac{1}{2} k_{\text {rad }}^{\max }\left[1+\operatorname{erf}\left(\frac{T-T_{R}}{\omega}\right)\right]$

Here the parameters are: $k_{\text {rad }}^{\max }$ maximum radiative conductivity $\left(0.345 \mathrm{Wm}^{-1} \mathrm{~K}^{-1}\right), T_{R}$ reference temperature (i.e. the temperature at which $0.5 \cdot k_{\text {rad }}^{\max }$ is reached, $\left.762 \mathrm{~K}\right)$ and a scaling factor $\omega(256 \mathrm{~K})$. The error function is denoted with erf. 


\subsubsection{Temperature dependency of thermal conductivity}

The temperature dependency of $k$ introduces a non-linearity and is thus accounted for iteratively, using subsequent substitution (or 'Picard's method', e.g. Hauck et al. 1999). The starting condition is a linear geotherm from surface temperature to $1200{ }^{\circ} \mathrm{C} \mathrm{LAB}$ (Fischer et al. 2010). After three iterations (i.e. when calculating the thermal conductivity using the temperature output of the second iteration) the procedure converges to less than $1 \mathrm{~K}$ variations in temperature and less than $0.4 \mathrm{~mW} \mathrm{~m}^{-2}$ variations in surface heat flow. See Section 1 of the Supporting Information for a test on the behaviour of this method.

\subsection{Iterative fit of heat generation}

Lacking direct measurements of radioactive heat production (RHP) throughout the whole crust thickness, estimates commonly rely on compilations of compositional data (Vilà et al. 2010; Artemieva et al. 2017; Hasterok \& Webb 2017; Hasterok et al. 2017).

The depth-wise distribution of radioactive elements is poorly modelled by simple functions (Jaupart \& Mareschal 2003) and is difficult to constrain from indirect observables. A decay with depth at large scale is commonly expected, owing to the progressive depletion of the lowermost crustal terms. Still, this model is challenged by evidence of heat-producing element rich bodies in the lower crust (Alessio et al. 2018), which suggest reconsidering the role attributed to crustal-scale differentiation. We therefore resort to using one bulk heat production for the whole crystalline crust, using an initial value that we derive from the lithotype medians reported in Vilà et al. (2010) and the reference crustal column of Wedepohl (1995).

This initial value of bulk heat production is then fitted to the measured surface heat flow, in cells where it is available, using the following scheme. The misfit between the forward-modelled surface heat flow and the measured one $\left(\Delta Q_{0}\right)$ is divided by the crustal thickness $\left(z_{\text {Moho }}-z_{\text {Sed }}\right)$, thus converting the heat flow misfit in a heat production per unit of volume value. We use this to guess a new bulk crustal heat production $(A)$. For the $n$th iteration, in the crustal column identified by $u, v$ grid position, this can be expressed as:

$A_{n}^{u, v}=A_{n-1}^{u, v}+\Delta Q_{0}^{u, v} /\left(z_{\text {Moho }}-z_{S e d}\right)^{u, v}$.

The resulting $A_{n}^{u, v}$ is then partitioned according to the upper to lower crust thickness ratio of Wedepohl (1995) column (thickness ratio upper to lower crust $=0.485$ ). This method constitutes an iterative subsequent substitution scheme. It is similar to the strategy adopted by Čermák \& Bodri (1986), where the unknown was the the heat flow at the base of the model. That method was subsequently referred to as a 'pseudo-inverse' technique (Čermák 1993).

The RHP in cells where no surface heat flow measurements are available is filled in by interpolating the fitted RHP values, using a natural neighbour interpolation (Sibson 1981). Undulations in crustal thickness are not accounted for when performing this interpolation.

We note that in a model with only 1-D heat conduction (along the vertical axis) and no temperature-conductivity dependence, this would lead to an exact solution in only one iteration. Horizontal heat conduction results in thermal gradient deviations around an hotter (more radioactive) crust, and the decrease in thermal conductivity for a larger temperature enhances this effect (for a synthetic example, see section 2 of the Supporting Information).
The radioactive heat production in the solid matrix of sediments is fixed at $0.93 \mu \mathrm{W} \mathrm{m} \mathrm{m}^{-3}$, from Vilà et al. (2010), and follows the same exponential compaction law of thermal conductivity. We set $A$ in the lithospheric mantle to $0.02 \mu \mathrm{W} \mathrm{m}^{-3}$ (Hasterok \& Chapman 2011).

\subsection{Thermal model input data}

\subsubsection{Surface heat flow}

We based this work on the data available in the Global Heat Flow Database of the International Heat Flow Commission, as available in the version maintained by Gosnold (2011). The raw records included 2780 points inside the study area (Fig. 6A). We edited them by discarding samples with heat flow above $300 \mathrm{~mW} \mathrm{~m}^{-2}(5$ points in the $2.5^{\circ}$ buffer around the study area, no points inside the study area) and below $15 \mathrm{~mW} \mathrm{~m}^{-2}$ (23 points in the buffer, 3 points inside the study area). Due to the whole-crust scale of this work compared with the typical measurement depth (less than a kilometre), no depth correction was applied to the records. We also did not apply any correction for the paleoclimatic effect, which in the area has been estimated ranging from 0 to $20 \mathrm{~mW} \mathrm{~m}^{-2}$ by Majorowicz \& Wybraniec (2011).

We corrected the records for the sampling bias toward high heat flow spots (Mareschal \& Jaupart 2013) and the short-wavelength components that may arise from near-surface phenomena. First, the study area is divided in a 40 by $40 \mathrm{~km}$ graticule, in local projected coordinates, and the median surface heat flow for each cell is calculated. Then the heat flow grid, which is treated as node-registered array, is convolved with a raised cosine kernel (the same kind used in the Moho inversion algorithm), resulting in a low-pass filtered heat flow grid. The filter kernel was sized for a cut-off wavelength of $320 \mathrm{~km}$, twice the cut-off applied to the Moho undulations.

The processed surface heat flow grid (shown in Fig. 6B) constitutes the input of the iterative accommodation of bulk crustal heat production, as described in Section 3.2.

\subsubsection{Lithosphere-asthenosphere boundary}

We extracted the bottom boundary condition, a $1200{ }^{\circ} \mathrm{C}$ LABisotherm, from the lithospheric thickness estimates provided in LITHO1.0 by Pasyanos et al. (2014), which are obtained from the inversion surface wave dispersion data. The points were interpolated to a regular grid with a bilinear 2-D spline interpolator (Wessel 2009), finding an approximate fit explaining 99.9 percent of the input data variance. The data and the interpolated extents are shown in Fig. 7.

The chosen temperature is an approximation arising from the thermal definition of the lithosphere: a thermal boundary layer, where heat transport is purely conductive, overlying a convecting mantle (Eaton et al. 2009; Fischer et al. 2010). This boundary temperature is therefore tied to a rheological definition, separating the mantle from the rigid lithospheric domain, where convection is not sustainable and tectonic plates move coherently (Steinberger \& Becker 2016). Common choices range from the mantle solidus temperature, which is pressure- and composition-dependent, to fractions of it, due to the evidence that even comparatively small melt percentages result in the seismic velocity drop associated with the LAB. The heat flow sensitivity to the chosen LAB temperature is small in respect to uncertainties in heat flow measurement or modelling therefore, a thermal-LAB depth inverted from surface heat flow has 


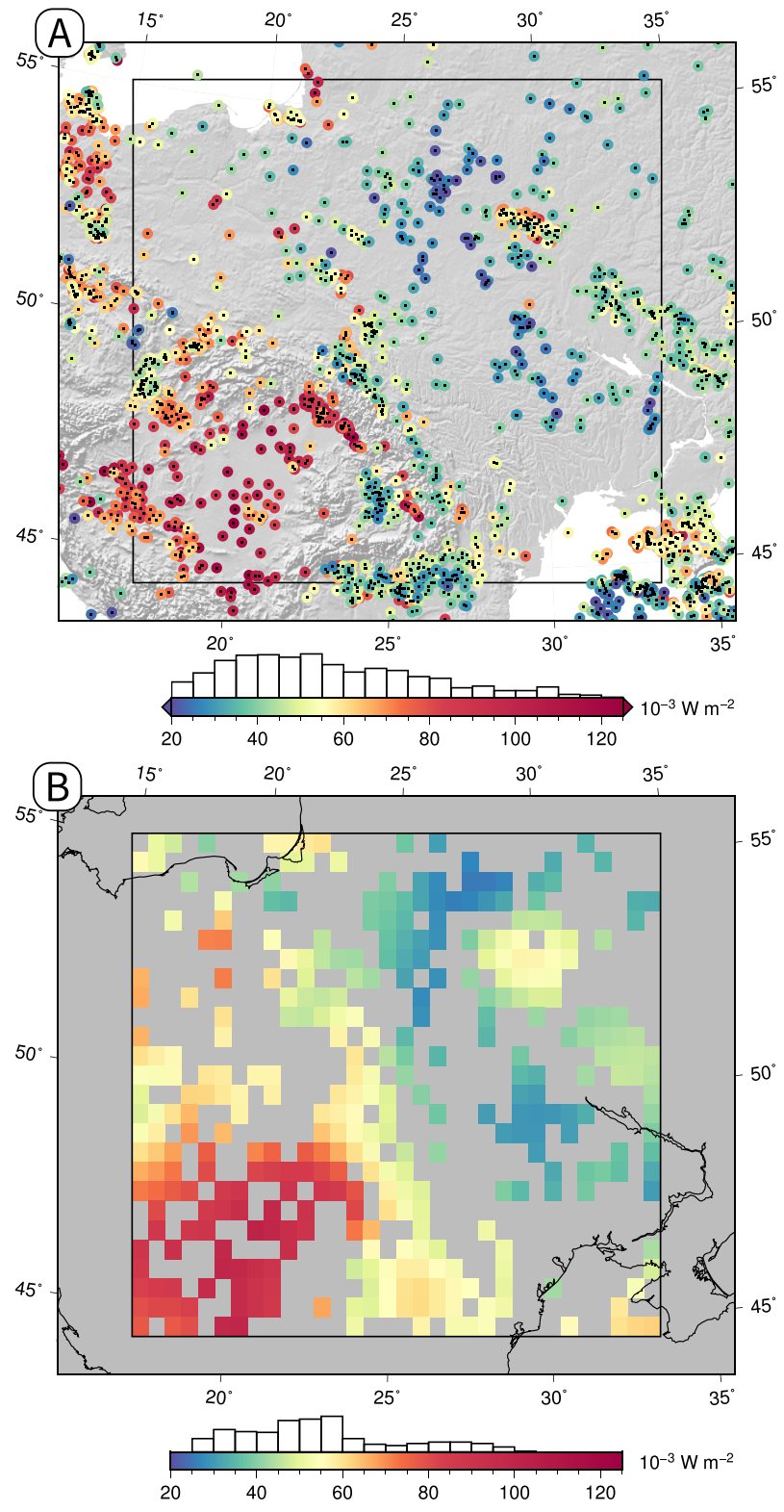

Figure 6. (A) Surface heat flow sample points, from Gosnold (2011). The histogram counts only the points inside the study area (inner rectangle). Note that there is considerable overlap in the most sampled spots, this is partly conveyed by the overlayed black dots. (B) The processed surface heat flow grid, after block-median and raised cosine low-pass filtering of the sample points.

an associated error in the order of tens of kilometres (Afonso et al. 2013). When tested in our forward modelling setup, the difference in terms of Moho heat flow of a thermal-LAB temperature of 1300 ${ }^{\circ} \mathrm{C}$ versus $1200{ }^{\circ} \mathrm{C}$ is $1.44 \mathrm{~mW} \mathrm{~m}^{-2}$, for the same $150 \mathrm{~km}$ deep LAB ( $Q_{M}$ of 17.05 and $15.61 \mathrm{~mW} \mathrm{~m}^{-2}$, respectively).

Pasyanos et al. (2014) included prior information in their surface wave inversion, as a starting model which was then perturbated. This data includes 'tectonic regions, crustal thickness from receiver functions and other information, upper mantle velocities from traveltime models, and thermotectonic information' (p. 2154, Pasyanos et al. 2014). We have preferred this model over other single-observable LAB models available in the area-e.g. receiver functions (Geissler et al. 2010), tomography inversion (Tesauro et al. 2009), seismic anisotropy (Plomerová \& Babuška 2010). A degree of dependence on prior data, including thermal models and Moho depth estimates, is unavoidable, since a common aspect of different techniques is requiring a correction for crustal effects (Jones et al. 2010). The adopted model provides a uniform coverage at an acceptable scale for the thermal footprint of LAB undulations, with a satisfactory resolving power of local features, such as the thin lithosphere underneath the Pannonian Basin $(50 \mathrm{~km})$.

\section{RESULTS OF GRAVITY REDUCTION AND INVERSION}

\subsection{Gravity reductions}

Using the procedure described in Section 2, we started from the gridded GOCE-GGM input signal shown in Fig. 3 A) and obtained a reduced signal, shown in Fig. 3B), through subtraction of the effects of global topography (Fig. 4A), far isostatic roots (Fig. 4B), and sediments (Fig. 4D). A histogram is plotted under each gravity signal map, its width coinciding with the colour-scale width. A continuous normal distribution, computed using the mean and standard deviation of the plotted data, is overlaid on each histogram. These two plots serve as a qualitative indicator of the signal distribution, while the quantitative statistics are shown in Table 1.

The cumulative effect of the reductions shifted the gravity signal towards positive values, resulting in a $80.8 \mathrm{mGal}$ increase of the average value.

The global topography effect (Fig. 4A) is negative over most of the study area, except the most central parts of large high topography areas: the Carpathians (centre-south of the study area), the Bohemian massif, and the easternmost portion of the Alps, at the western edge of the study area. The average topography in the area, from the EARTH2014 model at full resolution, is $220 \mathrm{~m}$. It ranges from $-113 \mathrm{~m}$ (small northern portion of the Black Sea, sampled on the southern edge) to $2109 \mathrm{~m}$ (Mt Moldoveanu, SE Carpathians).

The crustal root effect outside of the study area ('isostatic effect', Fig. 4B) is dominated by a east-west negative gradient, ranging from 68 to $54 \mathrm{mGal}$ over a $20^{\circ}$ longitude range. The north-south gradient is negligible.

The sediment thickness (Fig. 4C) ranges from zero to $16.3 \mathrm{~km}$, with an average of $3.1 \mathrm{~km}$. The western half of the area is characterised by thick sedimentary covers: between the Caledonides Foredeep and the Baltic Basin (NW corner, $11 \mathrm{~km}$ maximum), and along the Carpathians Foredeep, up to the very deep, but localised, Focşani Depression (16.3 km maximum). The Pripyat-Dnieper-Donets basin lies in the north-eastern part of the area. Basement depth reaches a maximum of $5 \mathrm{~km}$ there.

The forward-modelled sediments effect, reaches a maximum of $-102 \mathrm{mGal}$ using our compaction parameters. The depth-dependent exponential decay of compaction implies that the highest sensitivity of the gravity effect occurs in the first $6-8 \mathrm{~km}$ of thickness, where both the basement depth and the density modelling are critical, with the variance in the latter dominating the gravity signal (Kaban et al. 2010).

The gravity footprint of masses at distance is such that the minimum sediment effect value is $-24.7 \mathrm{mGal}$, instead of zero, even over areas with little to no sedimentary cover.

We assumed a uniform sediment compaction model and a set of depth-dependence parameters which, albeit a realistic compromise, does not reflect the exact characteristics of any of the basins in the study area. This unmodelled variability is a source of uncertainty, 


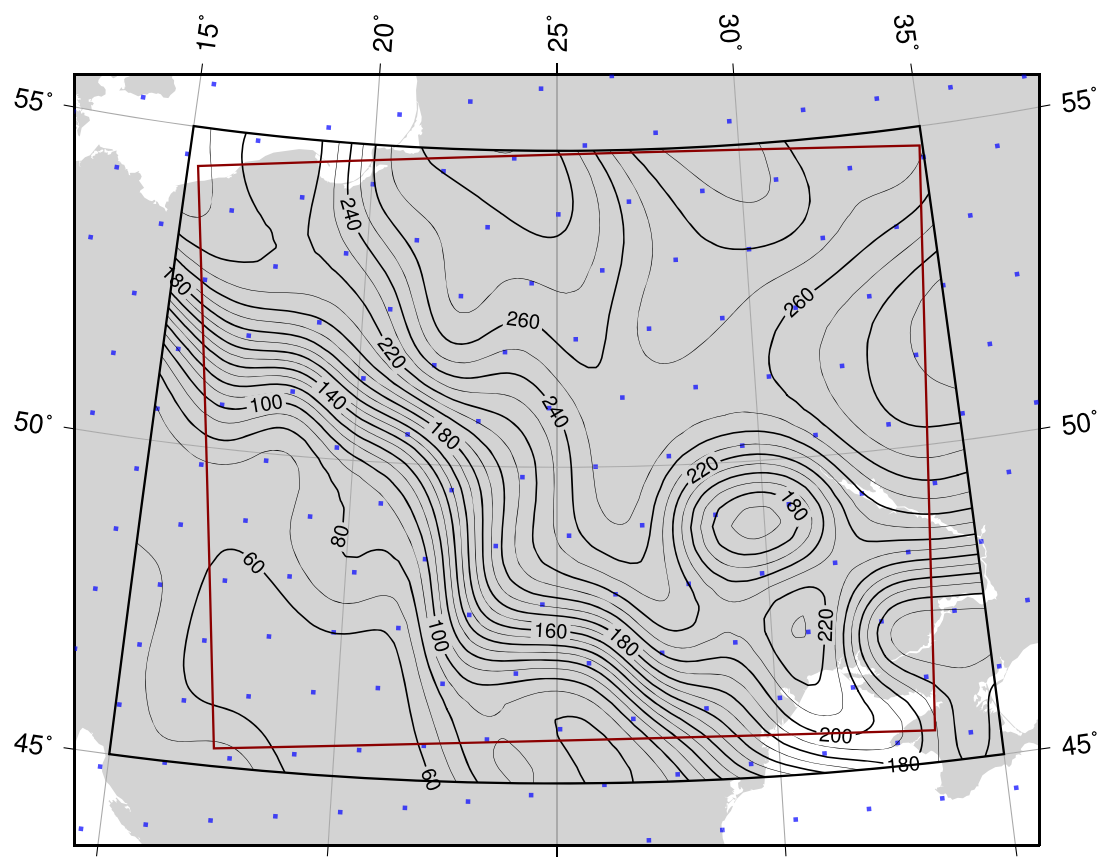

Figure 7. Depth of lithosphere-asthenosphere boundary (LAB) in km, as provided in LITHO1.0 (Pasyanos et al. 2014). Black polygon: interpolation extents. Red polygon: extents of our thermal model. Blue squares: LITHO1.0 data nodes.

Table 1. Descriptive statistics of the input gravity signal, of its reductions, and of the inversion results (Moho depth and gravity residuals). GD, gravity disturbance, from the global gravity model. LPF, raised cosine low-pass filter, applied during the inversion algorithm.

\begin{tabular}{|c|c|c|c|c|c|c|}
\hline & & Min & $\operatorname{Max}$ & Mean & Median & St. dev. \\
\hline \multicolumn{7}{|l|}{ Input data } \\
\hline GD, unprocessed & $\mathrm{mGal}$ & -38.0 & 87.6 & 18.5 & 18.1 & 20.6 \\
\hline Topographic effect & $\mathrm{mGal}$ & -121.5 & 19.6 & -80.4 & -85.4 & 20.7 \\
\hline Isostatic effect & $\mathrm{mGal}$ & 53.6 & 69.0 & 62.4 & 62.8 & - \\
\hline Sediments thickness & $\mathrm{km}$ & 0 & 16.3 & 3.1 & 2.6 & 2.6 \\
\hline Sediments effect & $\mathrm{mGal}$ & -104.5 & -24.1 & -62.8 & -65.0 & 19.7 \\
\hline GD, reduced & $\mathrm{mGal}$ & 46.77 & 186.6 & 99.3 & 98.8 & 24.6 \\
\hline GD, reduced, mean removed & $\mathrm{mGal}$ & -52.5 & 87.3 & 0 & -1.2 & 24.6 \\
\hline \multicolumn{7}{|l|}{ Inversion results } \\
\hline Inverted Moho depth (no LPF) & $\mathrm{km}$ & 23.2 & 81.5 & 44.2 & 43.7 & 4.9 \\
\hline Inverted Moho depth (160 km LPF) & $\mathrm{km}$ & 34.2 & 51.7 & 44.2 & 44.0 & 2.6 \\
\hline Residuals (no LPF) & $\mathrm{mGal}$ & -1.8 & 1.7 & 0.0 & 0.0 & 0.2 \\
\hline Residuals (160 km LPF) & $\mathrm{mGal}$ & -19.6 & 17.2 & 0.1 & 0.2 & 5.2 \\
\hline
\end{tabular}

which is usually addressed with integration with local well data, where available. The depth-density curve that Kaban et al. (2010) provide for the Pannonian Basin $\left(\phi_{0}=0.4\right.$ and $p=2.375 \mathrm{~km}$, while ours is $\phi_{0}=0.5$ and $p=4 \mathrm{~km}$ ) describes sediments which are less porous at the surface and that compacted faster with increasing depth. This means a smaller gravity correction for the same sediment thickness.

The sediment correction computed over the entire study area with those parameters is on average $22.8 \mathrm{mGal}$ smaller, up to a maximum of $48.8 \mathrm{mGal}$, over the absolute maximum of sediment thickness, the aforementioned Focşani Depression. The standard deviation of the difference is $9 \mathrm{~W} .4 \mathrm{mGal}$. Over the Pannonian Basin (about $5.2 \mathrm{~km}$ of sediments), our correction is $33 \mathrm{mGal}$ larger. Therefore, the inverted crustal thickness using Kaban et al. (2010) compaction model is consistently thicker, on average by $842 \mathrm{~m}$. Resorting again to the Pannonian Basin as a benchmark, the estimate with those parameters is up to $2.4 \mathrm{~km}$ thicker. In absolute terms, this means that the compaction model we adopted results in a $39.0 \mathrm{~km}$ Moho there, while the basin-specific one results in $41.2 \mathrm{~km}$ - even our less compacted model is not enough to fully explain the Pannonian Basin thinning as we discuss afterwards (Section 4.3).

\subsection{Moho estimate}

The left map of Fig. 5 shows the input data for the inversion routine. The dataset was obtained by removing the mean value of the reduced gravity signal and projecting it on a local UTM grid. Removing the mean value complies with the fact that the reference depth is equal to the expected Moho average depth. This way we interpret the reduced input gravity signal as due to deviations of the crust-mantle interface from its average value in the study area. The inversion result, reprojected to WGS84 coordinates, is shown in Fig. 8. Loss of edges occurs due to convergence of meridians, since the projection to the UTM grid is cropped to a rectangular domain (the extents are compared in Fig. 2, area B and C). The $160 \mathrm{~km}$ low-pass filter results 

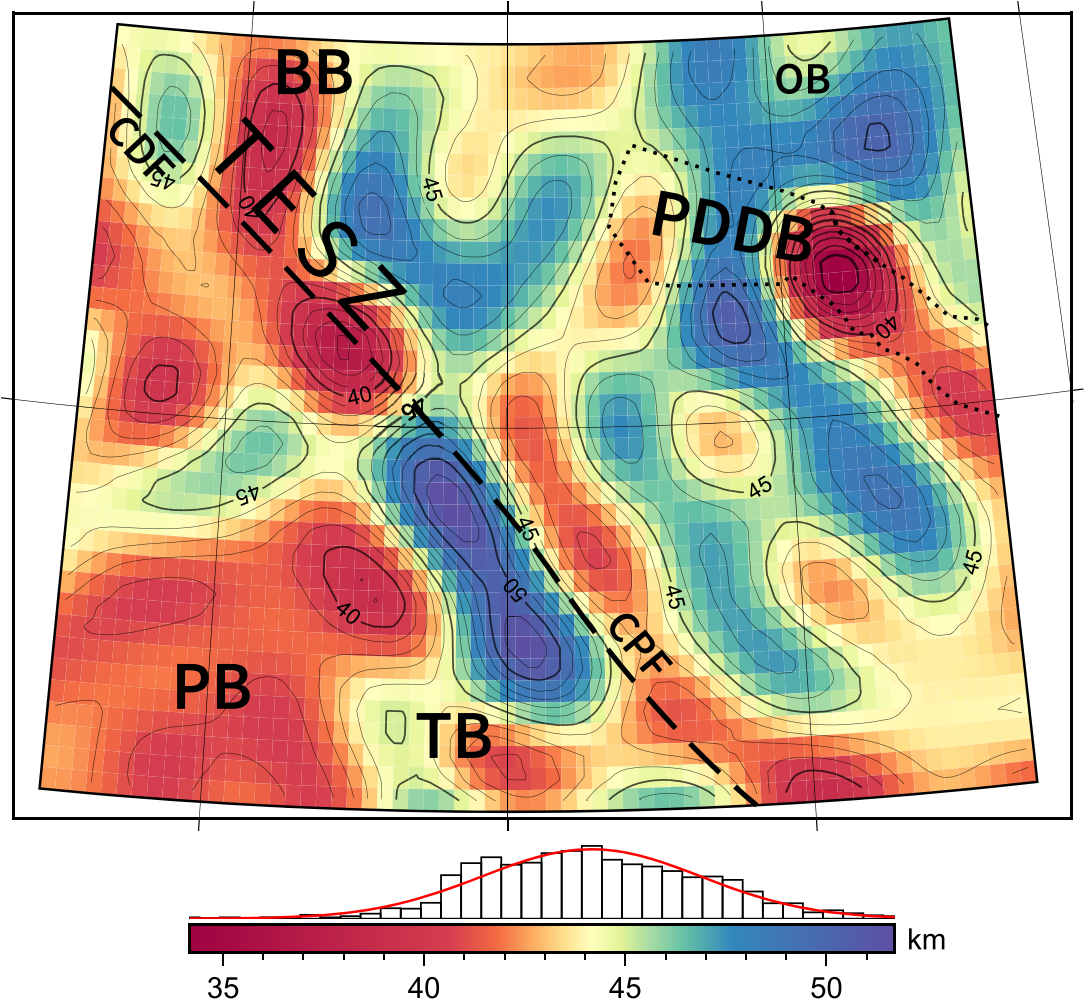

Figure 8. Moho depth as obtained from the inversion, contour interval $1 \mathrm{~km}$. Some of the geological features of Fig. 1 are shown: TESZ, Trans-European Suture Zone; CDF, Caledonides Foredeep; CPF, Carpathians Foredeep; TB, Transylvania Basin; PB, Pannonian Basin; PDDB, Pripyat-Dnieper-Donets basin; BB, Baltic Basin.

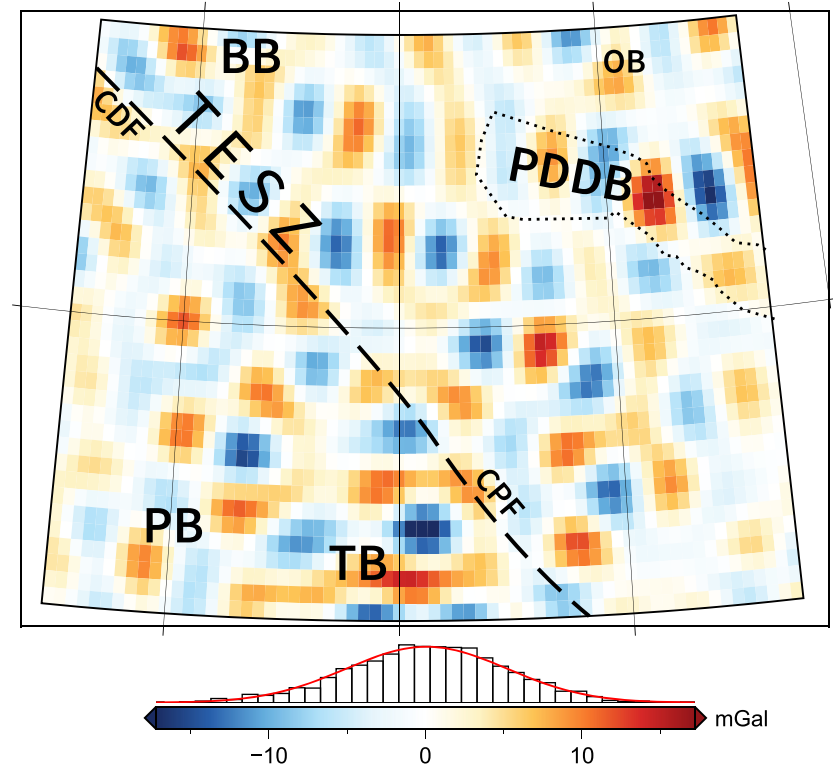

Figure 9. Inversion residuals: input gravity signal minus forward-modelled Moho undulation effect. Labelled features: see Fig. 8.

in residuals (i.e. the difference between the input gravity signal and the forward-modelled signal of the Moho estimate) ranging from -19.6 to $17.2 \mathrm{mGal}$, shown in Fig. 9. As shown in the statistics of Table 1, the residuals are negligible when no Moho low-pass filter is applied. This comes at a cost for the Moho estimate morphology, which exhibits local spikes of up to $23.2 \mathrm{~km}$ (minimum depth) and $81.5 \mathrm{~km}$ (maximum depth) before filtering. The final RMS misfit at the 10th iteration of the inversion algorithm is of 4.96 and $0.24 \mathrm{mGal}$ with and without low-pass filtering, respectively.

The Moho estimate that we obtained from inversion exhibits a thickening under the East Carpathians up to $51.7 \mathrm{~km}$ and up to $46.4 \mathrm{~km}$ under their northwest portion. The two sectors are interrupted by a relatively shallow saddle $(44.2 \mathrm{~km})$ at $49^{\circ} \mathrm{N} 22^{\circ} \mathrm{E}$.

A dominant northwest to southeast lineament is observed in the whole area, parallel to the TESZ. This could be discerned already in the input data, even before integration with the LITHO1.0 density contrast, which too shows a sharp NW-SE gradient across the suture zone.

Crustal thinning in the Caledonides Foredeep (CDF) and the Baltic Basin (BB), in the northwest sector of the area, reaches $38.0 \mathrm{~km}$. Underneath the longitudinally central part of the PripyatDnieper-Donets Basin (PDDB), the Moho rises up to $34.2 \mathrm{~km}$ locally. This thinning coincides with the Chernigov High, attributed to lower crustal mafic intrusions (Starostenko et al. 2018). Relatively thin crust (not exceeding $41.1 \mathrm{~km}$ ) persists eastwards of this local minimum, following the basin shape. It is interrupted westwards, instead, by a $48 \mathrm{~km}$ thick lineament orthogonal to the basin longitudinal axis.

We observe a thin crust under the Pannonian Basin (PB, southwest corner of the study area), never exceeding $41.8 \mathrm{~km}$ and reaching a local minimum of $38.9 \mathrm{~km}$ at $48^{\circ} \mathrm{N} 22.75^{\circ} \mathrm{E}$.

\subsection{Comparisons and critical aspects}

We adopt three different crustal models as benchmarks for our Moho depth estimate: the European Moho depth by Grad et al. (2009), the global GOCE-based model GEMMA by Reguzzoni \& Sampietro 
(2015) and the global lithospheric model LITHO1.0 by Pasyanos et al. (2014), which is based on surface wave dispersion. While the existence of completely independent models is unlikely, we expect a satisfyingly low degree of interdependence between these three, since they are based on different observables and strategies. These models and the differences from our estimate are shown in the maps of Fig. 10. We express the difference as our depth estimate minus the compared Moho.

The Moho depth by Grad et al. (2009) is the result of a large compilation of data from different methods (seismic reflection and refraction, receiver functions, tomography, joint seismic-gravity inversion), which where harmonised using relative weights. The model is accompanied by an uncertainty map, obtained from error estimates provided with data or from method-dependent assumptions, when the former were not available. It is the highest resolution model among these three.

The model by Reguzzoni \& Sampietro (2015), a global estimate of crustal thickness (and associated uncertainty), is based on data from GOCE, albeit with a different strategy from the one used here, including a novel inversion algorithm. It is by design highly independent from seismic data ('weakly constrained'), requiring only at least $M+1$ a priori Moho depths for an Earth divided in $M$ geological provinces.

We already used the LITHO1.0 (Pasyanos et al. 2014) model in our procedure: in the gravity reduction phase to compute a global crustal root effect ('isostatic effect') and in the inversion, where it provided the reference depth (average Moho depth in the study area) and the starting $\Delta \rho$ map. For these reasons, care must be taken in interpreting the comparison: e.g. the average difference is almost zero due to the chosen average reference depth.

We performed each comparison by downsampling the higher resolution grid to the lower resolution one, between our model and the compared one. Therefore, the Moho by Grad et al. (2009), which is provided on a $0.1^{\circ}$ grid, was downsampled to our $0.25^{\circ}$ grid; the Moho by Reguzzoni \& Sampietro (2015), provided on a $0.5^{\circ}$ grid was left as is and we downsampled our Moho to $0.5^{\circ}$. The comparison with LITHO1.0 was also performed on a $0.5^{\circ}$ grid, due to the non-rectangular tessellation of its original $1^{\circ}$ grid.

We summarise the difference range, mean, median, and standard deviation in Table 2 . The mean difference is directly controlled by the inversion reference depth parameter. It is positive (i.e. our Moho is deeper) for both Grad et al. (2009) and Reguzzoni \& Sampietro (2015) models, by 3.7 and $5.0 \mathrm{~km}$, respectively. This partly explains the consistently positive difference over the areas of thin crust. The distribution of differences against the three models is never symmetric: the difference between mean and median indicates a positive skew for Grad et al. (2009) and Reguzzoni \& Sampietro (2015) and a negative skew against the Moho of Pasyanos et al. (2014).

In terms of geological structures, our Moho depth model uniformly under-estimates the crustal thinning under the Pannonian basin: it reaches a minimum thickness ranging from 25 to $35 \mathrm{~km}$ in all the three compared models, while ours stops at $39 \mathrm{~km}$. Such a discrepancy may be explained by an insufficient correction for the sedimentary infill (which would require an even less compacted depth-density model, as discussed before) or by the complex Moho structure in extensional settings (e.g. due to underplating, see O'Reilly \& Griffin 2013), which is resolved differently by seismic methods.

The thickened root of the Carpathians is not resolved in the Moho by Grad et al. (2009), while it is present in our model and in the ones by Reguzzoni \& Sampietro (2015) and Pasyanos et al. (2014).
Its absence in the seismic model could be an artefact of locally poor coverage, a strong point for adopting gravity-derived models even in relatively well-surveyed areas.

We observe a thin NW-SE lineament, from the centre of the study area towards the lower half, in the GEMMA model (B), which is not resolved by the other models. It is also resolved by our model, and corresponds to a similar lineament in the GOCE data, then enhanced by the sediment correction. There is a $5-10 \mathrm{~km}$ positive misfit between GEMMA and our model, along this lineament. We speculate it may be originated by the different sediment reduction models, which the authors also applied before inversion. A thinner crust may result from a larger estimate (in thickness and/or in density) of the effect of the infill of the Carpathians Foredeep.

The misfits are uniformly less over the NE portion of the study area, roughly corresponding to the Russian Platform. The sensibly thinner crust of the Pripyat-Dnieper-Donets rift is resolved only by the GEMMA model, while it is fainter in the Moho by Grad et al. (2009). Our model also resolves that, albeit with the aforementioned underestimation of thinning. The discrepancy with GEMMA can be attributed to their use of geological provinces, through a variable density scale factor for each one. Such a strategy allows to accommodate the sharp differences in Moho contrast of different tectonic regimes, albeit with the added issues of depending on surface data.

Some small-scale Moho undulations in the Russian Platform are resolved by ours and the first two compared models, albeit with different magnitude. They are not present in the LITHO1.0 Moho and are the source of the large localised negative misfits (up to $15 \mathrm{~km}$ ). The absence of such small features (about 1 arcdeg across) can be attributed to the lower resolution of LITHO1.0.

The misfit with the other models arises due to the unaccounted density variations throughout the crust, which bias the inversion results, and from density variations in the mantle that we are not separating from the crustal contribution. The former, the intracrustal masses, can be partly addressed with data integration, where available: it is the case of the sediment stripping reduction we computed and applied. This can prevent some of the larger systematic errors, such as estimating a thick crust to fit the negative anomaly caused by the low-density infill of a basin. Still, the choice of a priori parameters, such as a general compaction model, does not take into account the large variance of geological heterogeneity. This can range from different compaction curves due to different basin histories Allen \& Allen (2013), to salt structures (which do not follow ordinary depth-dependence curves), to circumstances which would require more detailed models (e.g uplifted and eroded sedimentary formations, resulting in outcropping rocks with negligible porosity).

The latter, the 'mantle effect', cannot be reliably separated by spectral means (e.g. by truncating the lowest spherical harmonic degrees of the GGM), since large near-surface structures and mantle contributions often overlap (Kaban et al. 2004). A viable option is computing a density distribution from a mantle model of velocity anomalies (e.g. Kuhn \& Featherstone 2005), which is the strategy adopted by Reguzzoni \& Sampietro (2015), who used the GyPSuM model (Simmons et al. 2010). We have chosen to not perform such kind of reduction, owing to the additional uncertainties involved and on its temperature dependency. We have taken into account only the lateral variation of the lithospheric mantle density, which we included in the 'isostatic correction' to calculate a global Moho contrast (see eqs 1 and 2). 
(A)
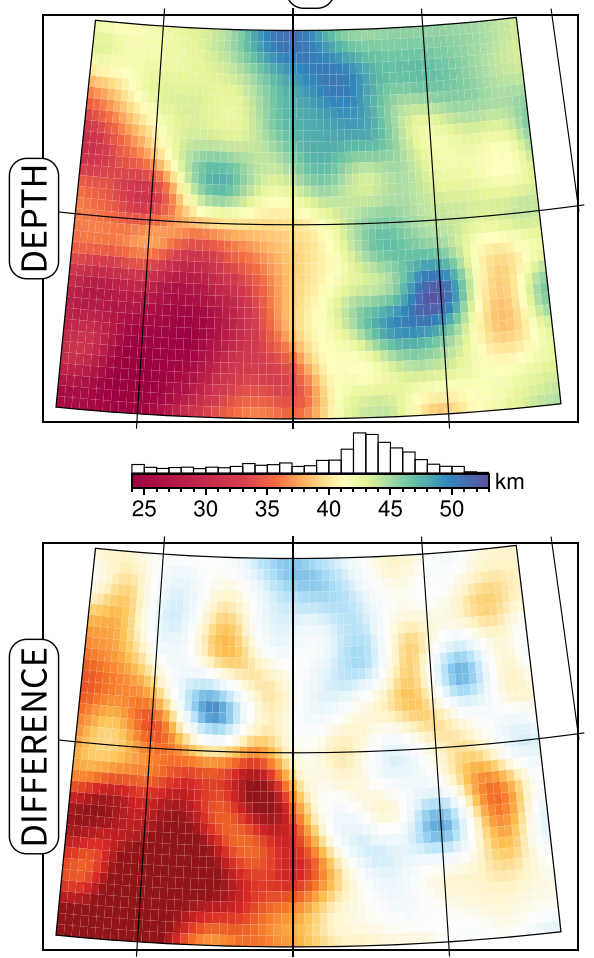

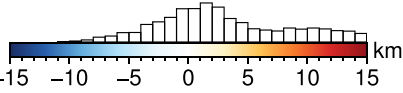

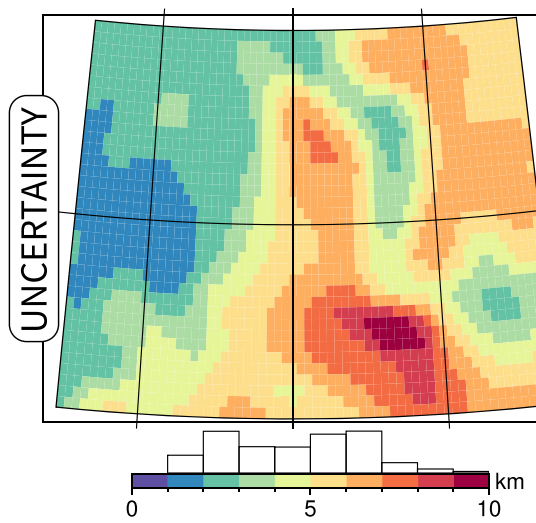

B

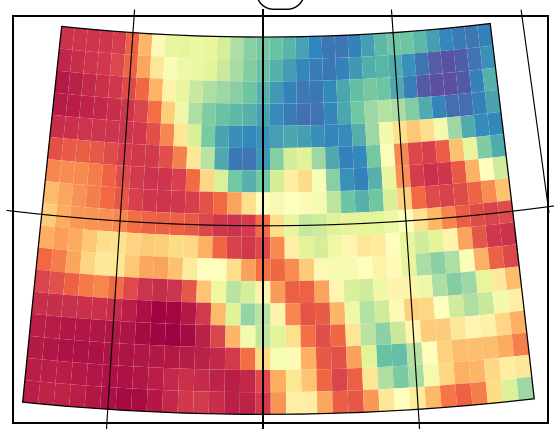

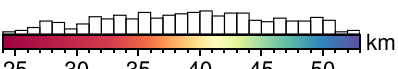
$\begin{array}{llllll}25 & 30 & 35 & 40 & 45 & 50\end{array}$

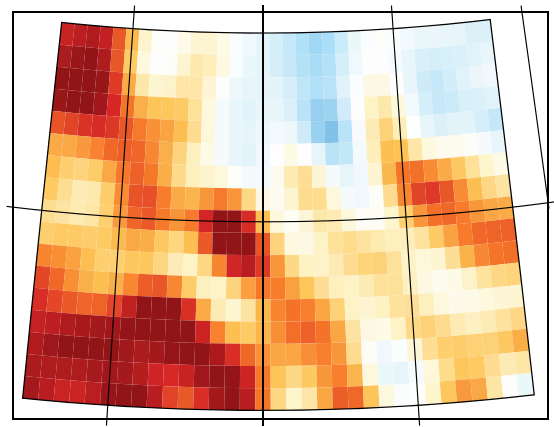

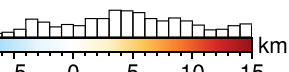
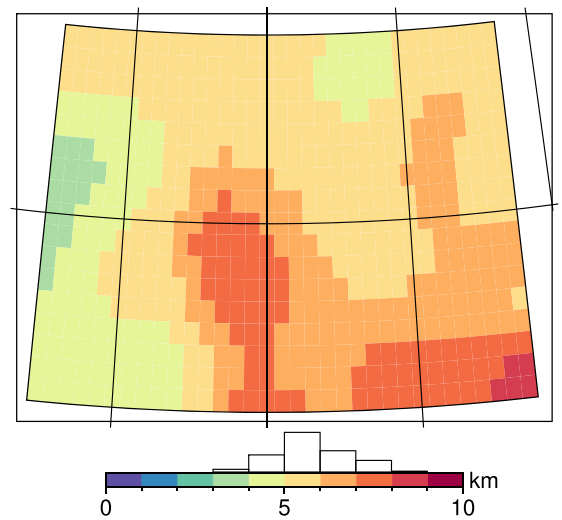

10
(C)
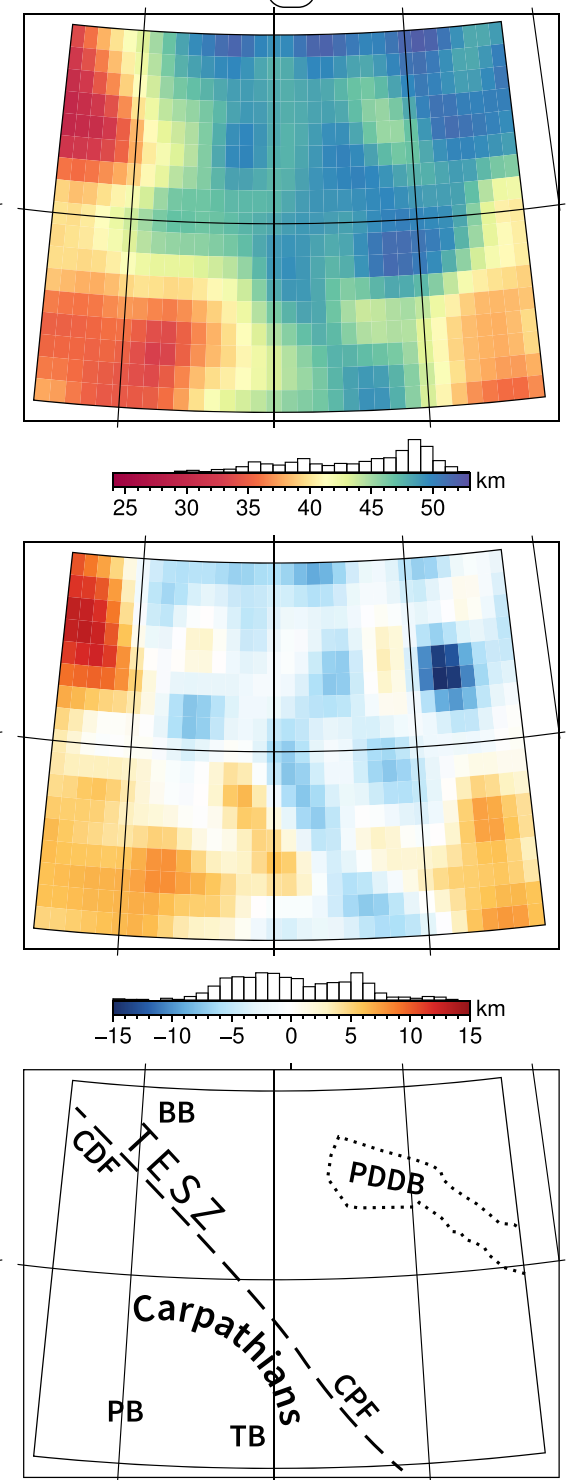

Figure 10. Comparisons with three selected crustal models: (A) European Moho depth by Grad et al. (2009), (B) GEMMA GOCE-based global Moho by Reguzzoni \& Sampietro (2015), (C) LITHO1.0 global surface-wave-dispersion model by Pasyanos et al. (2014). First row: Moho depths. Second row: differences, expressed as our depth estimate minus the compared Moho. Third row: uncertainty estimates (not available for LITHO1.0 depths). Lower-right corner: geological features, see Fig. 8.

Table 2. Statistics on differences between our Moho depth estimate and the three benchmarks. Our estimate minus the compared Moho.

\begin{tabular}{lccccc}
\hline Crustal model & Min & Max & Mean & Median & St. dev. \\
\hline (A) Grad et al. (2009) & -10.1 & 18.3 & 3.7 & 2.4 & 6.2 \\
(B) Reguzzoni \& Sampietro (2015) & -7.7 & 17.4 & 5.0 & 4.7 & 5.7 \\
(C) Pasyanos et al. (2014) & -14.6 & 13.1 & 0.1 & 0.6 & 4.9 \\
\hline
\end{tabular}

\section{THERMAL MODELLING RESULTS}

\subsection{Heat flow data}

The filtered and gridded surface heat flow measurements (shown in Fig. 6, B) highlight two distinct thermal regimes, which after filtering are distributed in a $80 \mathrm{~mW} \mathrm{~m} \mathrm{~m}^{-2}$ wide range. There is a southwest to northeast gradient across the TESZ lineament, albeit complicated by small wavelength variations. The cells with highest values are clustered in the Pannonian Basin, where considerable variance is observed $\left(70-105 \mathrm{~mW} \mathrm{~m}^{-2}\right)$. The lower-than-average 
Table 3. Summary of the adopted thermal parameters. For a detailed explanation of laws and symbols, refer to Section 3.1. SCLM: Sub-Continental Lithospheric Mantle. Abbreviatiated sources: V: Vilà et al. (2010), H: Hasterok \& Chapman (2011), C: Chapman (1986), X: Xu et al. (2004).

\begin{tabular}{lll}
\hline Layer & Heat production $(\mathbf{A})$ & Thermal conductivity $(\mathbf{k})$ \\
\hline Sediments & exponential compaction & exponential compaction [eq. (6)] \\
& $\phi_{0}=0.55, p=2.5 \mathrm{~km}$, & $\phi_{0}, p:$ see $A$, \\
& $A_{g r}=0.93 \mu \mathrm{Wm}^{-3}[\mathbf{V}], A_{p f}=0$ & $k_{g r}=3 \mathrm{Wm}^{-1} \mathrm{~K}^{-1}, k_{p f}=0.6 \mathrm{Wm}^{-1} \mathrm{~K}^{-1}$ \\
\hline Upper crust & initial guess $1.74 \mu \mathrm{Wm}^{-3}[\mathbf{V}]$ & temperature and depth dependent [C, eq. (7)] \\
& & $k_{0}=3.0 \mathrm{Wm}^{-1} \mathrm{~K}^{-1}$, \\
& $b=\left(1.5 \cdot 10^{-3}\right)^{\circ} C^{-1}, c=\left(1.5 \cdot 10^{-6}\right) m^{-1}$ \\
\hline Lower crust & initial guess $0.37 \mu \mathrm{Wm}^{-3}[\mathbf{V}]$ & temperature and depth dependent $[\mathbf{C}$, eq. (7)] \\
& & $k_{0}=2.6 \mathrm{Wm}^{-1} \mathrm{~K}^{-1}$, \\
& & $b=\left(1.0 \cdot 10^{-4}\right)^{\circ} C^{-1}, c=\left(1.5 \cdot 10^{-6}\right) m^{-1}$ \\
\hline SCLM & $0.02 \mu \mathrm{Wm}^{-3}[\mathbf{H}]$ & temperature and pressure dependent, sum of: \\
& & - lattice conduction term $[\mathbf{X}$, eq. (8)] \\
& - radiative term [H, eq. (9)] \\
\hline
\end{tabular}

heat flow cells in the Russian Platform include a superimposed local maximum $\left(54.9 \mathrm{~mW} \mathrm{~m}^{-2}\right.$ ) coinciding with part of the PripyatDnieper-Donets rift. We note that this also coincides with a spot of thin crust (up to $35 \mathrm{~km}$ ).

Block-median gridding and low pass filtering decreased the standard deviation from 23.6 to $17.81 \mathrm{~mW} \mathrm{~m}^{-2}$. The average of the raw samples is $57.1 \mathrm{~mW} \mathrm{~m}^{-2}$, it becomes $54.8 \mathrm{~mW} \mathrm{~m}^{-2}$ after processing. Processed surface heat flow in the grid cells range from 26.2 to $98.0 \mathrm{~mW} \mathrm{~m}^{-2}$. For comparison, the global average continental surface heat flow is estimated at $64 \mathrm{~mW} \mathrm{~m}^{-2}$, as concordantly found with different strategies by Davies \& Davies (2010) and Pollack et al. (1993). No-data cells cover 58 per cent of the study area.

\subsection{Iterative forward modelling output}

The top row of Fig. 11 shows the output after the first iteration of the thermal model ('first guess', as described in Section 3.2). The surface heat flow misfit between the forward model (left map, $\left.Q_{0, \text { first }}\right)$ and the measurements is shown in the central map ( $\left.\Delta Q_{0, \text { first }}\right)$. The average misfit is $-7.5 \mathrm{~mW} \mathrm{~m}^{-2}$, with a standard deviation of $13.7 \mathrm{~mW} \mathrm{~m}^{-2}$. Those results indicate how the crust thickness alone can explain only a limited part of the variance in the observed heat flow, confirming a common finding (e.g. Jaupart et al. 2016). The first-guess was run with a laterally uniform crustal heat production per unit of volume of $1.04 \mu \mathrm{W} \mathrm{m}^{-3}$, partitioned between the upper crust $\left(1.74 \mu \mathrm{W} \mathrm{m}^{-3}\right)$ and the lower crust $\left(0.37 \mu \mathrm{W} \mathrm{m}^{-3}\right)$. The right-hand map $\left(Q_{0, \text { first }}\right)$ shows the crustal heat flow contribution, expressed as the difference between the heat flow at the base of the sediments layer and the heat flow at the crust-mantle boundary. At this stage, it is directly proportional to crustal thickness.

The bottom row of Fig. 11 shows the same variables of the first row, at the sixth crustal RHP fitting iteration. We adopt the same colour scale. Here practically all the signal in the surface heat flow is modelled, leaving a mean misfit of $0.005 \mathrm{~mW} \mathrm{~m}^{-2}$ (standard deviation $0.038 \mathrm{~mW} \mathrm{~m}^{-2}$ ). The converging behaviour of RMS misfit over the six iterations is shown in the top plot of Fig. 12: it decreased from 13.0 to $0.03 \mathrm{~mW} \mathrm{~m}^{-2}$. The trend of the distribution of fitting heat production is shown in the bottom plot of the same figure. While the median value of heat production is reduced by of $0.26 \mu \mathrm{W} \mathrm{m}^{-3}$ from start to end, the fitted values are distributed between 0.18 and $2.18 \mu \mathrm{W} \mathrm{m}^{-3}$ (minimum to maximum) after the last iteration. The width of their distribution appears directly connected to the decreasing misfit shown in the top plot. The map on the right in Fig. 13 shows the fitted heat production values, for each crustal column. Their distribution is skewed toward low values, resembling the empirically observed asymmetrical distribution of rock heat production values (Vilà et al. 2010; Artemieva et al. 2017; Hasterok \& Webb 2017), which has been modelled with a log-normal distribution sometimes (e.g. Jokinen \& Kukkonen 1999; Huang et al. 2013).

The spatial distribution of crustal heat production shows a firstorder correlation with surface heat flow. This is a direct consequence of fitting all the variance not arising from the thickness of the crust and lithosphere with heat production, as we have shown before. Still, deviations from a pure correlation between heat flow and heat production arise from the contribution of crustal thickness, as can be seen by comparing the crustal heat flow contribution, in the right map of Fig. 11, against the thickness of the crystalline crust (left map of Fig. 13). We resort to the cross-plots of Fig. 14 to better show this.

The line overlain to scatter plots (A) to (C) represents the results of the first guess, in a perfect crustal thickness to crustal heat flow relationship, with no lateral variations in RHP. Two behaviours of departure from the first guess line can be observed: the first, a cluster which has most of its points confined between 35 and $40 \mathrm{~km}$ of thickness, increased its RHP value with respect to the first guess. It corresponds to those heat flow values found in the extensional basins, as shown in the maps of Fig. 11. The other, which involves the remainder of points, is considerably scattered along a trend of inverse proportionality between crustal thickness and RHP, opposite to the first guess. This weak negative relationship is a common finding of studies on relationships between heat flow and crustal thickness (Čermák 1993; Mareschal \& Jaupart 2013).

As described before, our RHP fill-in method relies on the interpolation of fitted RHP, which is available in cells where surface heat flow measurements are available, over cells where there are none. We assumed that $A$, the RHP per unit of volume, is uncorrelated to crustal thickness. Therefore, the interpolation does not take into account Moho undulations. As shown in plot (B) of the crossplots figure (Fig. 14), we observe a negative proportionality between Moho depth and fitted RHP. This a-posteriori observation suggest that a correlation between the two exist and could be exploited to further constraint the RHP fill-in. Nevertheless, it should be interpreted with caution. There is an issue with the attribution of heat flow misfit to crustal or mantle sources, which we address in the next section.

In Fig. 14(D) we plotted our fitted RHP against the bulk density of LITHO1.0 (Pasyanos et al. 2014) crystalline crust, computed 

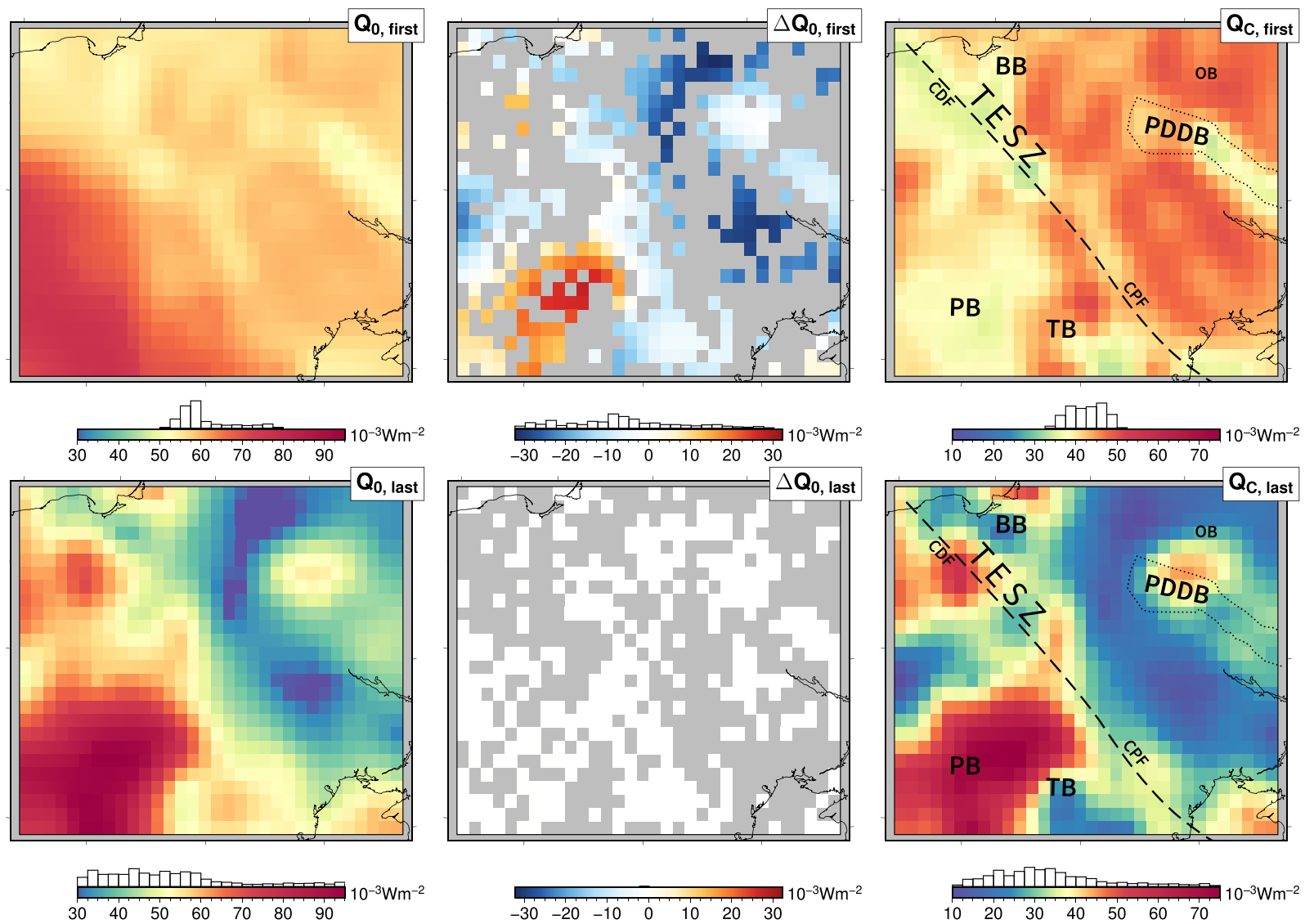

Figure 11. Results of the iterative fit on the thermal model, in terms of surface heat flow. Top row: first iteration, only a priori crustal heat production. Bottom row: last iteration. Left-hand column: surface heat flow; middle column: misfit between heat flow measurements and forward-modelled heat flow; right-hand column: crustal (radiogenic) component of surface heat flow.

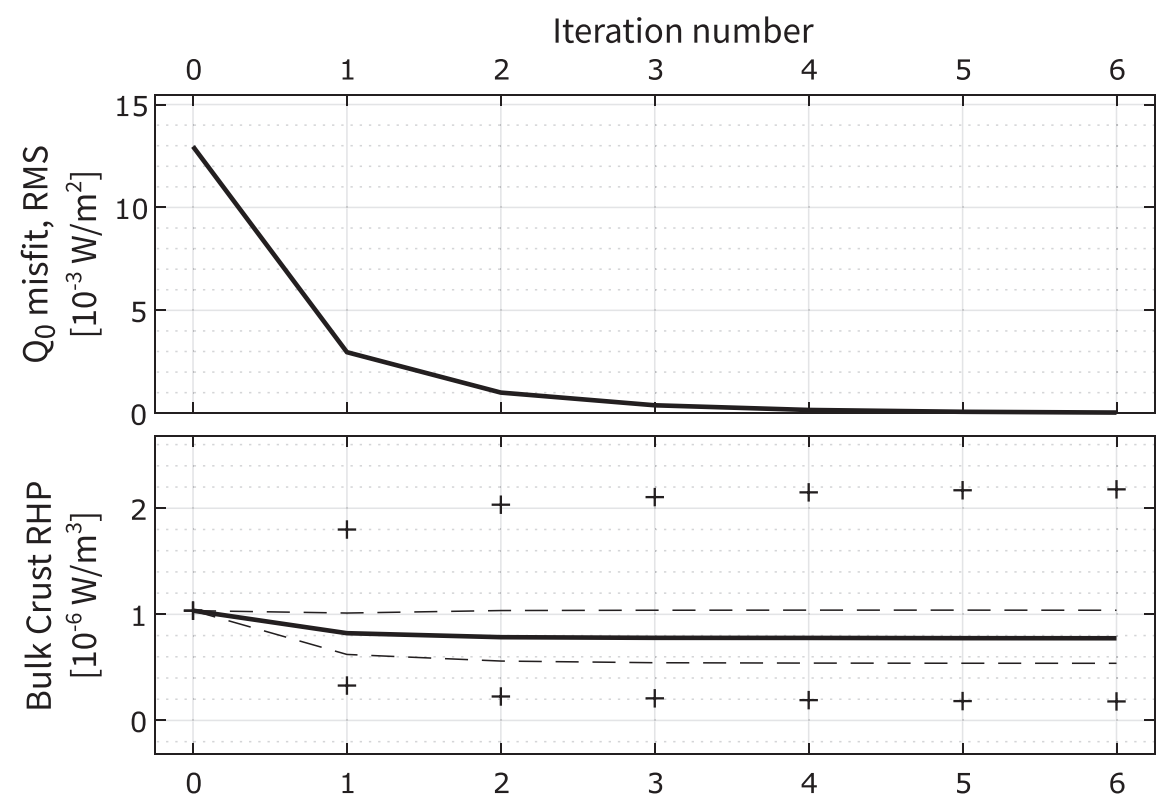

Figure 12. Behaviour of the subsequent substitution fitting procedure in six iterations, plus the first guess. RMS surface heat flow misfit (top) and radiogenic heat production in the upper crust (per unit of volume, bottom). The tick line denotes the median, the two dashed lines the first and third quartiles, respectively, the crosses minimum and maximum values. 

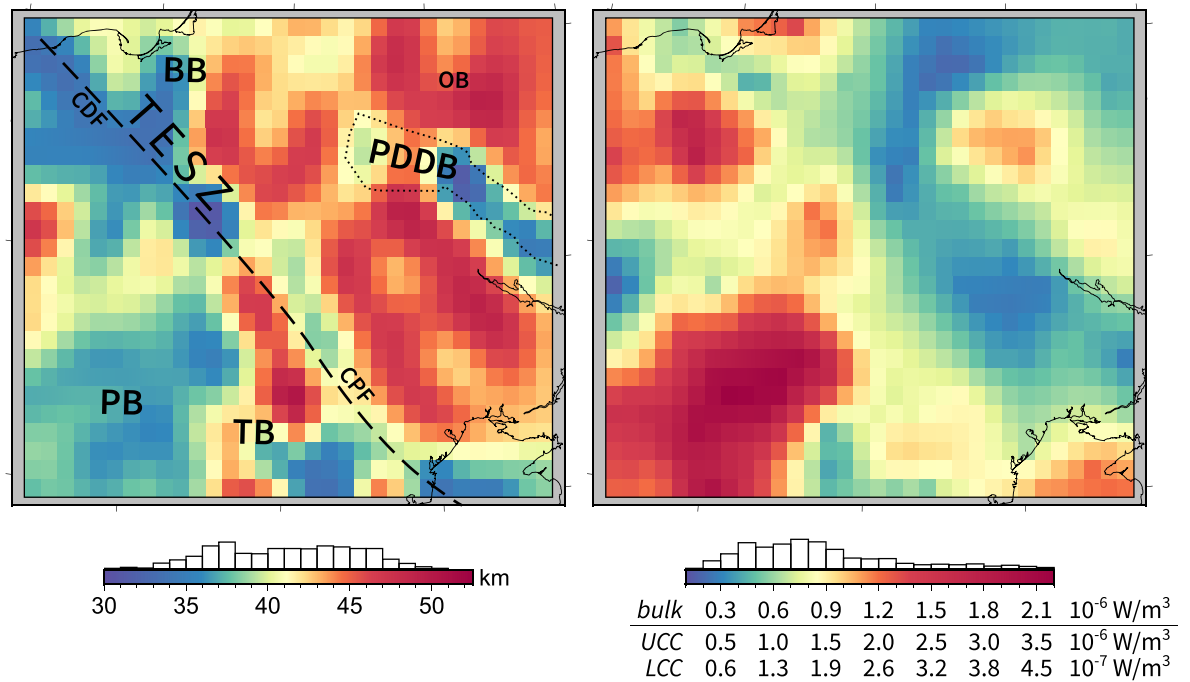

Figure 13. Fitted radiogenic heat production (RHP) in the crystalline crust, per unit of volume. Left-hand panel: thickness of crystalline crust: Moho depth minus sediment basement depth; right-hand panel: RHP: bulk and partitioned to upper and lower crystalline crust (note that the lower crust RHP unit is one order of magnitude smaller). Geographical labels: see Fig. 8.

by thickness-weighted averaging of the three crustal layers. We did so in order to compare our result to the density to heat production relationship provided by Hasterok \& Webb (2017): $\log _{10} A=$ $-0.0027(\rho-2700)+0.53$ (plotted in black). In contrast to our indirect estimates, their results are based on geochemical data of more than 100000 samples. We perfomed a log-linear fit to our data, obtaining the following relationship, plotted in purple:

$\log _{10} A=-0.0019(\rho-2700)+0.20$.

The $2 \sigma$ confidence interval of our fit is -0.0022 to $-0.0015\left(\log _{10} \mu \mathrm{W} \mathrm{m}^{-3}\right)\left(\mathrm{kg} \mathrm{m}^{-3}\right)^{-1}$ for the slope and 0.14 $0.26 \mu \mathrm{W} \mathrm{m} \mathrm{m}^{-3}$ for the intercept. $R^{2}$ is 0.1274 . We excluded the nodes with a bulk density lower than $2780 \mathrm{~kg} \mathrm{~m}^{-3}$, since they are underrepresented in our study area (less than 7 per cent of total nodes, clustered in the southeast corner). A negative relationship between density and RHP can be observed - it can be attributed to the increased content in heat producing elements in less dense, more felsic rocks (Hasterok \& Webb 2017). The two fits, albeit different, overlap in their uncertainty interval. A version of the scatter plots of Fig. 14 in which a colour scale is used to depict each node density, and a map of the bulk density of the crystalline crust in the study area are provided in the Supporting Information (section 5, Fig. S.14).

We also compared our RHP estimate with the $\mathrm{V}^{\mathrm{P}}$ to heat production conversion provided in Hasterok \& Webb (2017), using their $\log$-linear relationship for the continental crust $\left(\log _{10} A=-0.70\left(V_{P}\right.\right.$ $-6)+0.48$ ). Due to the relationship between density and $\mathrm{V}^{\mathrm{P}}$, the pattern is similar to what we just discussed concerning density. A similar trend of negative correlation is observed, with the our result shifted toward lower values: $\log _{10} A=-0.56\left(V_{P}-6\right)+0.19$. The geochemistry-based linear fit and the one that we obtained by linear regression on our inverted data again overlap in their $2 \sigma$ uncertainty interval. The $\mathrm{V}^{\mathrm{P}}$-converted RHP is consistently higher than our estimate over the whole area (mean $+0.42 \mu \mathrm{W} \mathrm{m}{ }^{-3}$ ), with a local maximum of $+1.84 \mu \mathrm{W} \mathrm{m}^{-3}$ in the southeastern corner of the area (local cluster with $\mathrm{V}^{\mathrm{P}}$ less than $6.2 \mathrm{~km} \mathrm{~s}^{-1}$ ). Our RHP estimate is higher than the converted one only in the Pannonian Basin (difference of up to $-0.59 \mu \mathrm{W} \mathrm{m}^{-3}$ ). A figure with a scatter plot of $\mathrm{V}^{\mathrm{P}}$ and RHP, accompanying maps and further details on the log-linear fit to our data are provided in the Supporting Information (section 6, Fig. S.15).

\subsection{Partitioning of heat flow between crust and mantle sources}

Since our strategy is based on the assumption that all the surface heat flow misfit can be attributed to omitted crustal heat production, we analyse what this implies for the partition between the crustal contribution $\left(Q_{\mathrm{C}}\right)$ and the basal, mantle-borne, heat flow component $\left(Q_{\mathrm{M}}\right.$, Fig. 15). This has also been referred to as 'partition coefficient'. Hasterok \& Gard (2016) expressed it as the basal to surface heat flow ratio. Here we adopt the crustal to surface heat flow ratio $\left(Q_{\mathrm{C}}: Q_{0}\right)$ as a partition metric. We also define the basal heat flow as the heat flow through the crust-mantle boundary, since we are including lateral variations of heat production in the lower crust. A larger ratio indicates a thermal regime dominated by crustal heat production.

The top plot of Fig. 16 shows how this partition varies through the iterations: the largest variation occurs between the first guess (iteration zero) and iteration one, where the median $Q_{\mathrm{C}}: Q_{0}$ drops by 8.6 points percent. No significant variation in the median occurs between iteration 1 and 6 . The range between the extreme values (denoted with 'plus' signs) and the interquartile range (between the first and thirt quartile, plotted with dashed lines) widen, with a trend that flattens after iteration 4.

The bottom plot of Fig. 16 represents the trend of $Q_{\mathrm{M}}$, which appears anticorrelated with the $Q_{\mathrm{C}}: Q_{0}$ ratio. This behaviour stems from the suppression of basal heat flow that is observed for an increase in crustal heat production. Basal heat flow, for a fixed radiogenic $Q_{\mathrm{C}}$, would be only controlled by the depth of the LABisotherm and the series thermal resistance of the LAB-to-surface path. A steeper geotherm (i.e. a warmer crust) decreases the thermal conductivity of the crust [see eq. (3.3) here and Chapman 1986], resulting in a lower $Q_{\mathrm{M}}$ for the same LAB depth. In addition, thermal refraction is observed around an hotter crustal body, since the steepest temperature path is not along vertical any more (for synthetic examples, see sections 2 and 3 provided in the Supporting Information). 

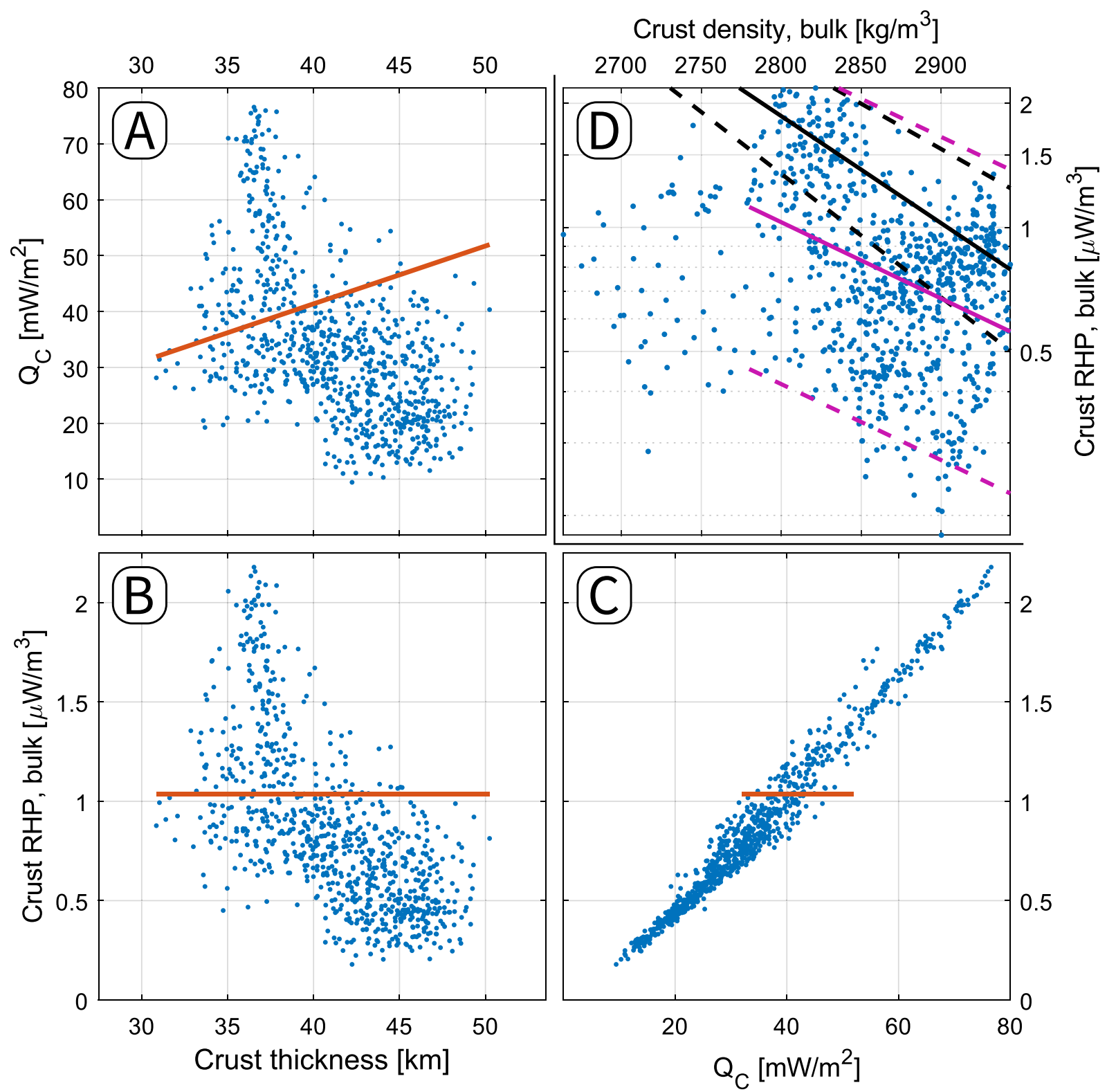

Figure 14. Cross plots between thickness of the crystalline crust (Moho depth minus basement depth), radioactive heat production (RHP) of the bulk crystalline crust, crustal component of heat flow $\left(Q_{\mathrm{C}}\right)$, and crust density. The line overlaid on scatter plots $(\mathrm{A})$ to $(\mathrm{C})$ represents the first guess, using the $a$ priori constant RHP. Plot (D): bulk density of the crystalline crust plotted against the radioactive heat production (RHP). The density-heat production relationship by Hasterok $\&$ Webb (2017) is plotted in black. Our fit is plotted in purple. Dashed lines depict upper and lower confidence bounds.

This implies that whenever a positive misfit in $Q_{0}$ (i.e. not enough crustal heat production) is fitted for, $Q_{\mathrm{M}}$ in the same model column will decrease in the subsequent forward modelling iteration. This will result in a positive misfit again, albeit smaller. The opposite happens for a negative misfit, whenever the forward modelled surface heat flow is higher than the observed.

Plotting the evolution of $Q_{\mathrm{M}}$ on a map (Fig. 15) provides further information on the spatial distribution of this variation, and its relationship with geology. The left-hand map (iteration zero, labelled $Q_{M, \text { first }}$ ) shows a thermal regime which is strongly controlled by the LAB morphology (Fig. 7): the warmer and thinner southwest European Phanerozoic lithosphere and the colder, thicker, platform across the suture zone. The local effect of overlying crustal structures can be already seen, superimposed. The middle map (sixth iteration, labelled $Q_{\mathrm{M} \text {, last }}$ ) highlights where the starting situation was conserved and where it was reversed. By comparing it with the iteration zero misfit map of Fig. 11 (middle top row), we see how the strongest transitions from high to low $Q_{\mathrm{M}}$ and vice versa are clustered on the areas of largest misfit. We thus attribute this reversal to the inverse dependence mechanism described before.

Overall, the local extremes in $Q_{\mathrm{C}}$, and their accompanying minimums in $Q_{\mathrm{M}}$ should be interpreted with caution: comparison with the geological settings suggests that they may be a symptom of overestimation of the $Q_{\mathrm{C}}: Q_{0}$ ratio, when the source of increased heat flow should be attributed to others factors, instead. This is most evident in the Pannonian Basin and, to a lesser extent, in the Pripyat-Dnieper-Donets basin and in the Caledonides Foredeep. This can be attributed to the persistence of non-stationary 

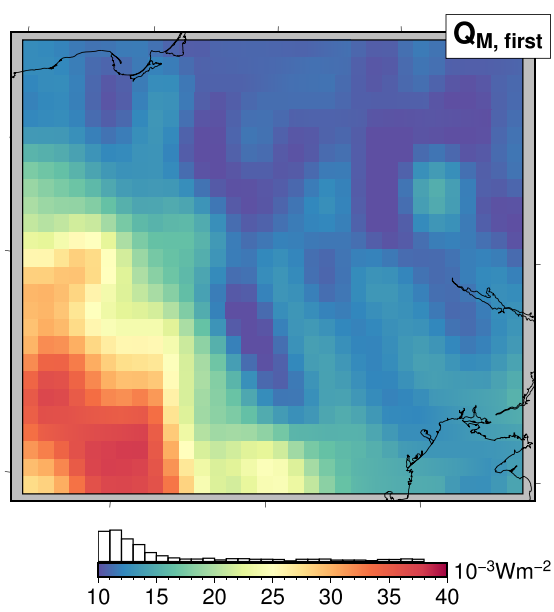
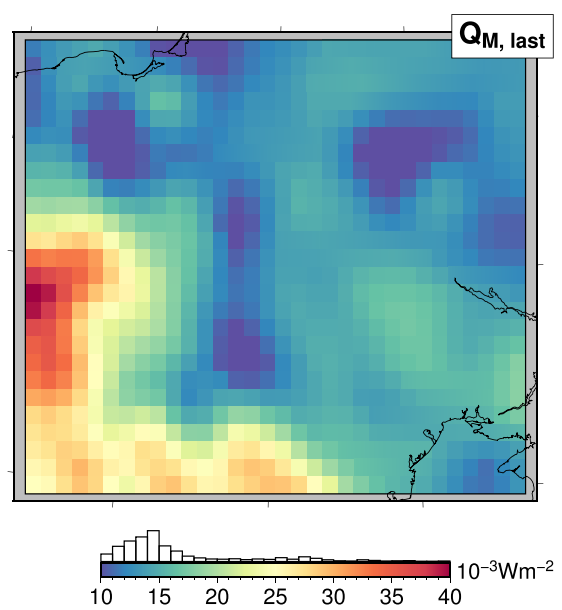
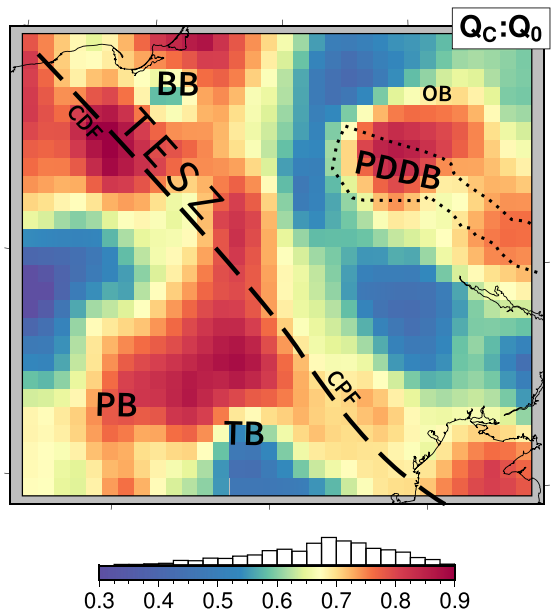

Figure 15. Basal heat flow $\left(Q_{\mathrm{M}}\right)$, at the crust-mantle boundary. Left-hand panel: $Q_{\mathrm{M}}$ at the first iteration (a priori parameters); middle panel: $Q_{\mathrm{M}}$ at the last iteration; right-hand panel: partition coefficient, expressed as the ratio between crustal component of heat flow $\left(Q_{\mathrm{C}}\right)$ and the total surface heat flow $\left(Q_{0}\right)$, at the last iteration.

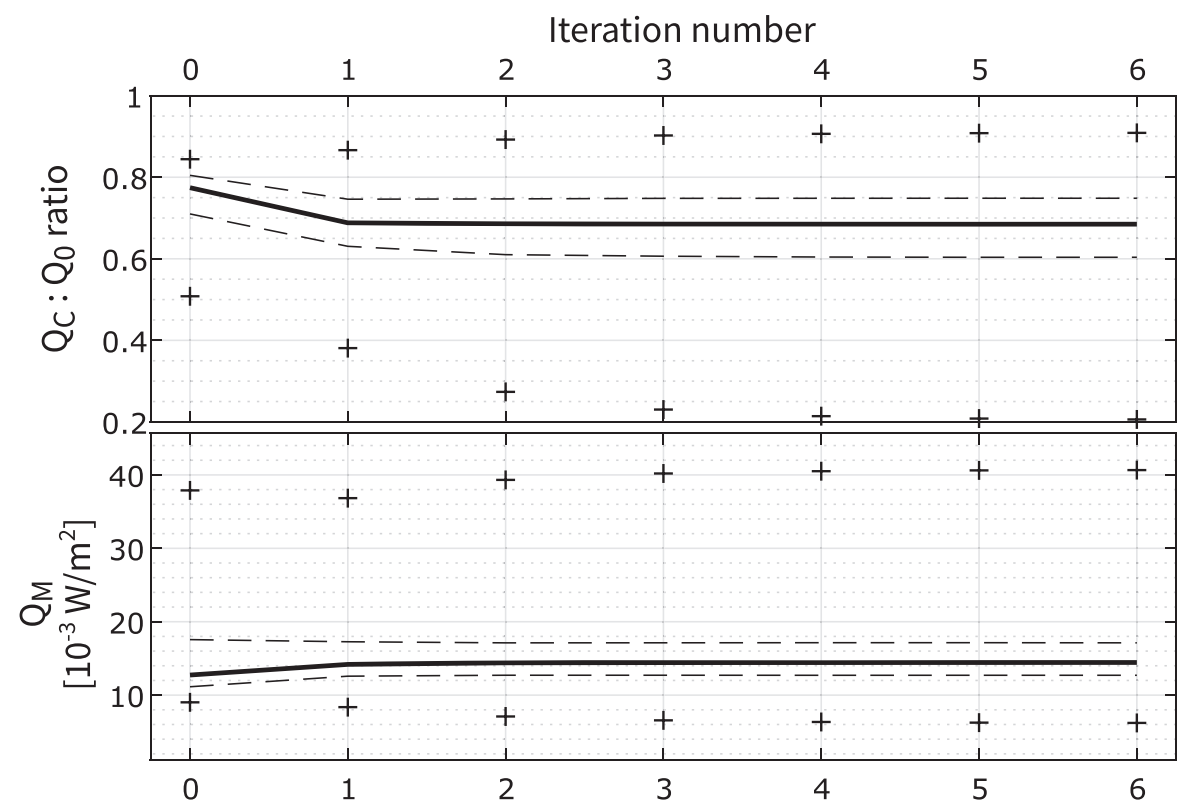

Figure 16. Top panel: ratio of the crustal heat flow component $\left(Q_{\mathrm{C}}\right)$ against the surface heat flow $\left(Q_{0}\right)$, as shown in the right map of Fig 15 . Bottom panel: heat flow at the crust-mantle boundary $\left(Q_{\mathrm{M}}\right)$. The distribution statistics at each iteration are plotted with different symbols. For a legend, refer to the caption of Fig. 12.

heat transport. The Pannonian Basin is expected to have significant departures from thermal equilibrium. We obtain a rough order of magnitude estimate with the end of its rifting phase, around $14 \mathrm{Ma}$ (Horváth et al. 2015) and the characteristic time scale for reaching quasi-steady state conditions, as defined in (Stüwe 2007). The $l^{2} / 2 \kappa$ rule, as provided in Stüwe (2007), with $l$ length scale and $\kappa$ thermal diffusivity, results in a time scale for reaching equilibrium on the order of $10^{2}$ Myr for a $10^{8} \mathrm{~m}$ length scale (lithospheric thickness).

We also note how spots of localised thinning of the crystalline crust (see Fig. 13, left-hand panel) result in enhanced $Q_{m}$, persisting through the iterations. This is the result of higher effective thermal conductivity of the LAB-to-surface path, since thermal conductivity is lower in the crust than in the lithospheric mantle. It is a phenomenon similar to the blanketing and chimney effects observed by Przybycin et al. (2015) for variations in sediment thickness.

\subsection{AA' section}

In Fig. 17 we plotted a 2-D slice under the AA' profile (shown in the geological setting map, Fig. 1). It encompasses the different thermal regimes encountered across the study area, which are dominated by the aforementioned southwest-to-northeast transition to older and colder lithosphere.

The effect of the crust, including sediments, is superimposed on the signal from lithospheric thickness. The thermal conductivity section shows the effect of thermal dependence of $k$ and its role in controlling $Q_{\mathrm{M}}$. The portions of hotter crust and lithosphere (e.g. the SW portion of the section) are accompanied by a strong reduction in $k$ in the upper crust and in the lithospheric mantle. The lower crust sees the concurrent effect of the temperaturedriven decrease of $k$ - a dependence which is an order of magnitude 

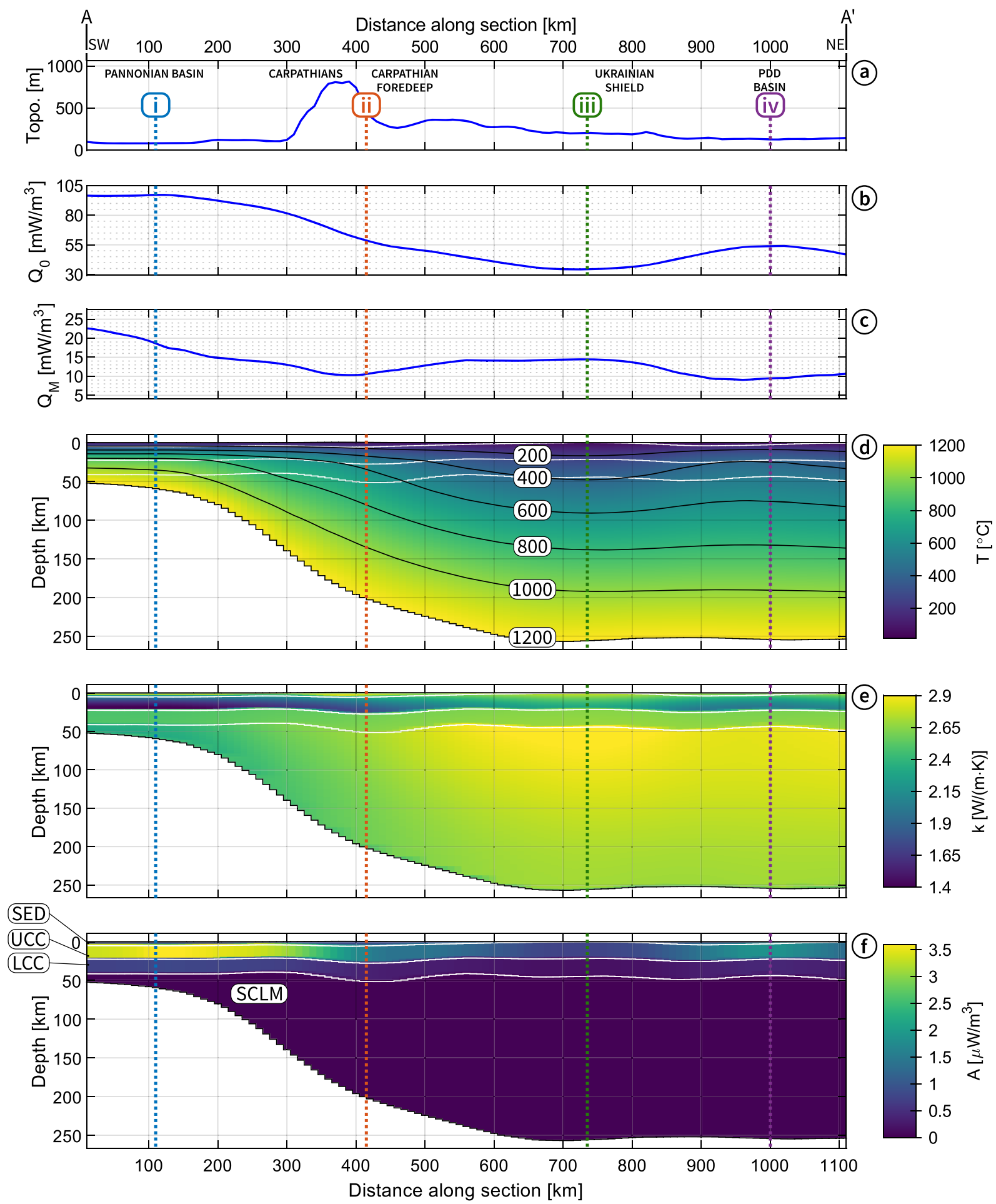

Figure 17. Thermal model section AA' (extents are shown in Fig. 1). (a) topographic profile. (b) $Q_{0}$, surface heat flow profile (c) $Q_{\mathrm{M}}$, Moho heat flow profile. (d) temperature slice. (e) thermal conductivity slice. (f) radiogenic heat production slice. Layer boundaries are shown in white and labelled on the left side of the bottom slice. Abbrevations: PDD, Pripyat-Dnieper-Donets basin; SED, sediments; UCC, upper crystalline crust; LCC, lower crystalline crust; SCLM, subcontinental lithospheric mantle.

weaker than in the upper crust, in the adopted Chapman (1986) model - and increase of $k$ due to rising pressure. The total effect is a slight increase in conductivity with depth, in concordance with the data shown in Chapman (1986). This depth-wise trend is clearly represented for four sample columns in the middle plot of Fig. 18. We must note how this outcome is strongly dependent on the reliability of the assumed temperature-conductivity relationships, therefore it should be interpreted only in conjunction with other 


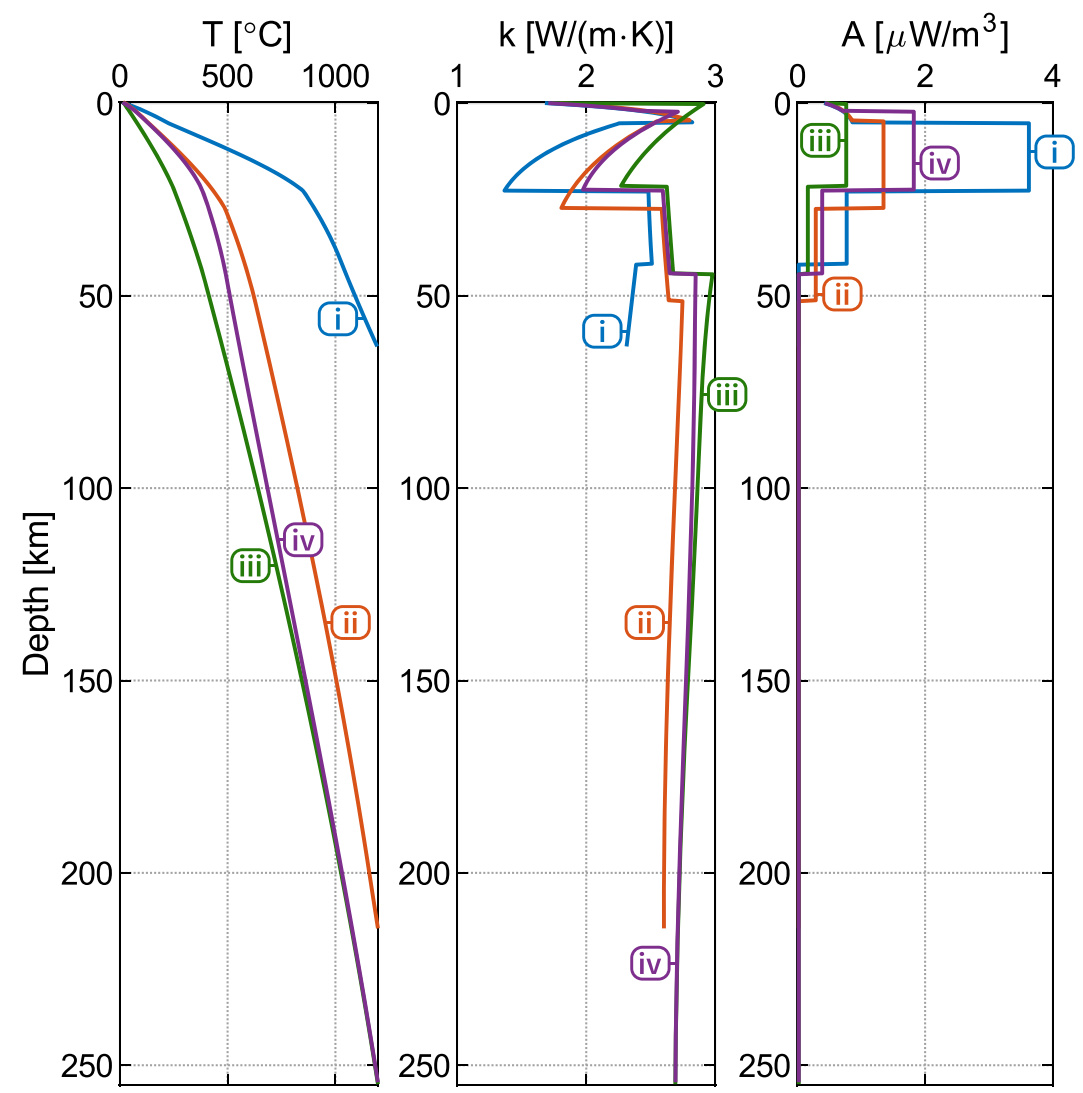

Figure 18. Plots of temperature, thermal conductivity and heat production in four columns of section AA' (Fig. 17). Colours and roman numerals refer to the corresponding labels in the section figure. (i) Pannonian Basin, (ii) Carpathians, (iii) Ukrainian Shield, (iv) Pripyat-Dnieper-Donets Basin.
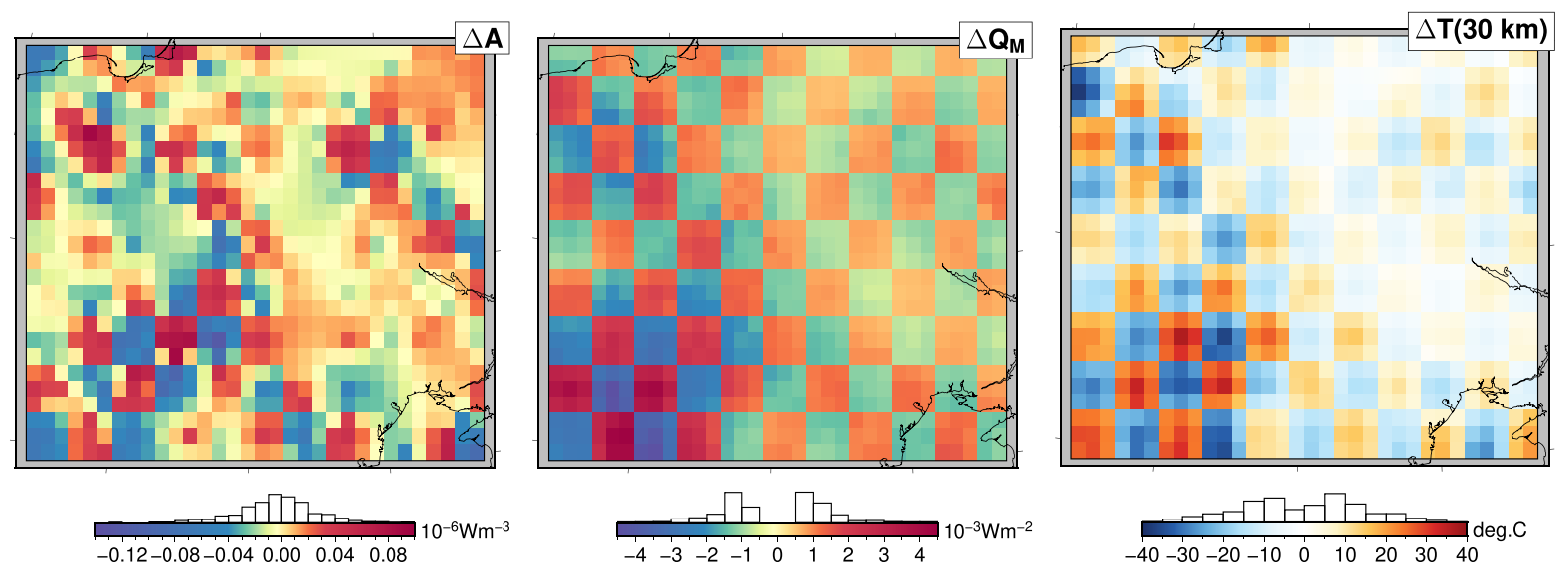

Figure 19. Checkerboard Moho test. Differences in bulk crustal RHP $(\Delta A)$, basal heat flow $\left(\Delta Q_{\mathrm{M}}\right)$, and temperature at $30 \mathrm{~km}$ depth $[\Delta T(30 \mathrm{~km})]$ are expressed as flat Moho (44 km) minus checkerboard Moho (40-48 km, $120 \mathrm{~km}$ square tiles).

temperature proxies (e.g. xenoliths, Curie depth, effective elastic thickness).

Thick sedimentary covers (Pannonian basin, Carpathians foredeep: columns $i$ and $i i$, plotted in blue and orange, respectively) further contribute in the reduction of the total thermal conductivity of the lithosphere, attenuating the effect of LAB undulations. $Q_{\mathrm{M}}$ exhibits a relative maximum across the Ukrainian shield (column iii, plotted in green), albeit being over a very thick lithosphere. There, a combination of thin sedimentary cover, a cold crystalline crust, and a relatively cold lithospheric mantle (note the depression in isotherms in plot d) result in a more conductive lithosphere overall.

\subsection{Sensitivity of the result to crustal thickness}

In Fig. 19 we present the comparison of the results obtained with a flat Moho (44 km, the average of our Moho depth estimate) and a synthetic 'checkerboard Moho'. The latter alternates between 40 and $48 \mathrm{~km}$ of thickness, on 120 by $120 \mathrm{~km}$ tiles. We plotted the 

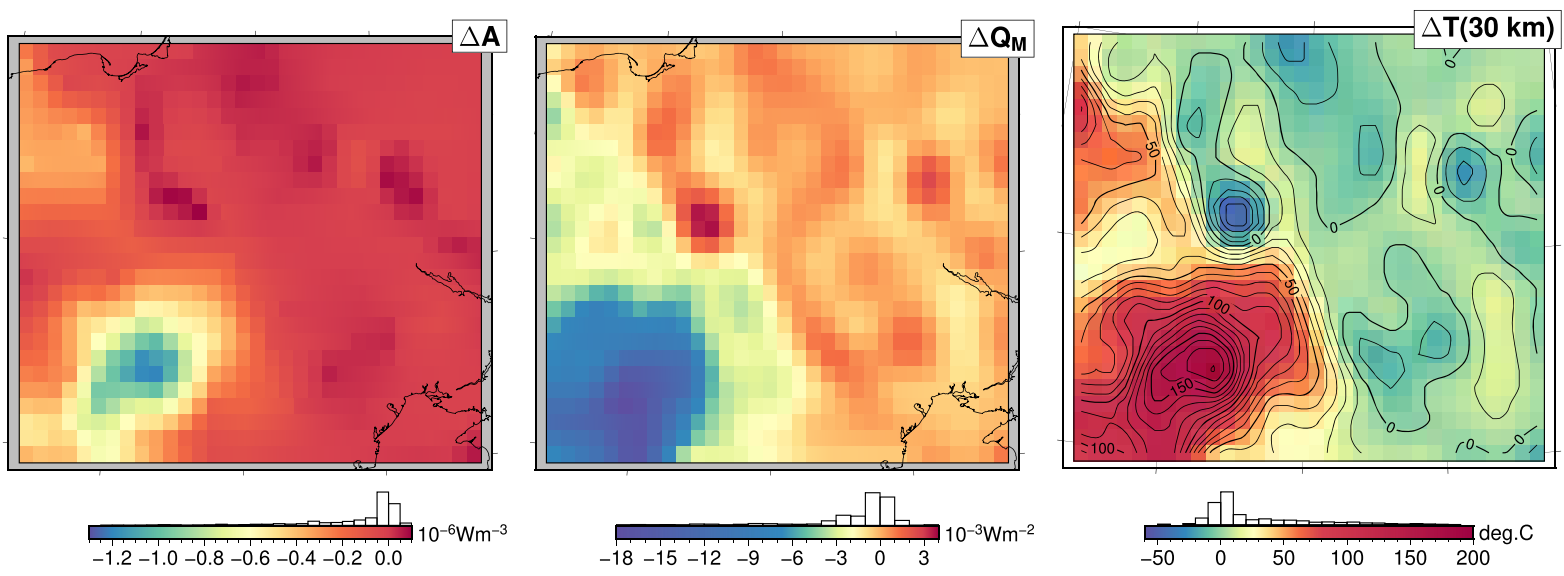

Figure 20. Thermal results comparison between our Moho model and the one by Grad et al. (2009). Differences in bulk crustal RHP ( $\triangle A$ ), basal heat flow $\left(\Delta Q_{\mathrm{M}}\right)$, and temperature at $30 \mathrm{~km}$ depth $[\Delta T(30 \mathrm{~km})]$ are expressed as results using our Moho minus results using the compared one. The southwest checkerboard tile is a thin tile $(40 \mathrm{~km})$.

difference between fitted RHP, basal heat flow, and temperature at $30 \mathrm{~km}$. The difference is expressed as the value obtained with the flat-Moho model minus the value obtained with the checkerboardMoho one, that is positive values indicate larger results in the latter. As a reference for the alternating pattern, the southwest corner is a thin tile (40-km-thick crust).

The differences in fitted RHP ( $\triangle A$, left-hand map of Fig. 19) are at most one order of magnitude smaller than the range of variation in RHP observed in our model. In the majority of cases, a difference of $\pm 0.04 \mu \mathrm{W} \mathrm{m}^{-3}$ in RHP per unit of volume is enough to compensate $\mathrm{a} \pm 4 \mathrm{~km}$ variation in crustal thickness. The RHP increases (negative difference) for a thinner crust. The sensitivity of RHP fitting with respect to the Moho model seems low-this is an expected consequence of all the non-crust-correlated RHP variance that we fitted for. We note that larger values (in absolute terms) are observed in cells where the $Q_{\mathrm{C}}: Q_{0}$ indicates a thermal regime dominated by the crustal contribution (larger values in the right-hand map of Fig. 15).

Differences in basal heat flow ( $Q_{\mathrm{M}}$, central map of Fig. 19) are of comparable magnitude to those observed in our thermal model. A thinner crust results in an increased $Q_{\mathrm{M}}$, and vice versa. There is a subtle variation superimposed on the checkerboard pattern, which becomes more evident in the temperature differences $[\Delta T(30 \mathrm{~km}$, right-hand map of Fig. 19]. These are distributed in a zero-average $\pm 37{ }^{\circ} \mathrm{C}$ range. A thinner crust tile results in increased temperature, and vice versa, following the same pattern observed with $Q_{\mathrm{M}}$. The differences attenuate from a full-range alternating pattern in the southwest portion of the area to almost zero in the northeast part. In contrast to what we observed with $\Delta A$, there is no evident relationship with $Q_{\mathrm{C}}: Q_{0}$, while the controlling factors appear to be the lithospheric thickness and surface heat flow (which are correlated).

We also tested using a different crustal model: the seismic Moho by Grad et al. (2009), that we already compared with our satelliteonly estimate in Fig. 10 and discussed in Section 4.2. In Fig. 20,we have plotted the differences of three modelling outputs, using the same scheme of the 'checkerboard Moho' figure. Those differences are expressed as: results using our Moho estimate minus results using Grad et al. (2009), that is a negative difference where the latter results in a larger value.

In the $\Delta A$ map of Fig. 20, we observe a local minimum of $1.2 \mu \mathrm{W} \mathrm{m}^{-3}$ in the Pannonian Basin. The shallower Moho by Grad et al. (2009) (24.4 km minimum, compared to $39.9 \mathrm{~km}$ in our Moho model) has been compensated with an higher RHP, to obtain the same $Q_{\mathrm{C}}$ with a smaller crustal volume. There are localised spots of positive $\Delta A$, corresponding to structures where our Moho model is thinner (see A) column plots in Fig. 10). The $Q_{\mathrm{M}}$ and $\Delta T(30 \mathrm{~km}$ maps show a similar pattern: the thinner crust of Grad et al. (2009) results in more basal heat flow under the Pannonian Basin and higher temperatures, up to $+180{ }^{\circ} \mathrm{C}$.

Crustal geometry therefore exerts significant effect on heat transport and temperature distribution, and, to a lesser extent, on the results of RHP fitting. Therefore, a reliable crust estimate appears of utmost importance in their modelling and in their applications, such as thermorheological forward modelling (e.g. Burov \& Diament 1995).

\section{CONCLUSIONS}

We have presented the outcome of a comprehensive gravity-thermal strategy: from the geophysical data reduction of a global gravity model relying on GOCE observations to a regional-scale estimate of crustal thickness, which we then included in a steady-state thermal forward model and a subsequent substitution radioactive heat production fitting technique. Our crustal thickness estimate and the available surface heat flow measurements acted as main constraints.

The gravity reductions that we computed and applied involve global modelling, through a combination of space-domain forward modelling and spectral-domain filtering to ensure full spectral consistency with the band-limited global gravity model. The Moho undulations that we obtained by inversion of the anomaly that we isolated resulted in a crustal thickness model which resolves most of the features found in the three benchmarks (Grad et al. 2009; Pasyanos et al. 2014; Reguzzoni \& Sampietro 2015), albeit with discrepancies arising from differences in methods and data.

The results show consistency with the thermal regime of the study region, a test box across the Trans-European Suture Zone, at a similar spatial scale as sensed by the gravity model. Control of the Moho undulations on the temperature distribution is evident, both in terms of heat production and in shaping the mantle-to-surface heat transport, including the effect thermal refraction around hotter and less conductive crustal bodies.

Overall, we assessed the suitability of a satellite gravity data to thermal model work flow, which is providing useful quantitative 
insights even when integration with other data is kept to a minimum. The unparalleled spatial homogeneity in sampling and data quality that satellite-only global gravity models provide is already used to estimate crustal thickness in areas devoid of surface data. This test has shown how the same approach can be extended to thermal modelling, improving the models of poorly covered areas.

A pitfall of crustal thickness inversion from gravity models is the omission of structures that are instead resolved by seismic methods, due to unmodelled parameters (e.g. density variations) and uncertainties in data reductions. In our test we deliberately avoided hard constraints from the seismic Moho models available in the area. We assessed the effects of the discrepancies between our Moho estimate and the model by Grad et al. (2009), in terms of thermal modelling results. The outcome indicated how the Moho depth is more critical the higher the reduced heat flow $\left(Q_{\mathrm{M}}\right)$ is, resulting in significant differences under part of the study area. While the magnitude of this difference is not detrimental to the thermal model reliability, it suggests that an accompanying uncertainty estimate would be beneficial.

Overall, the thermal modelling strategy that we have designed for this proof of concept has proven fit for its purpose. The nonuniqueness in heat flow isolation (separating the crustal radiogenic contribution from other concurring thermal factors, such as basal heat flow, long wavelength near surface effects, and tectonic transients) calls for a multivariate inversion problem. This could be addressed by using an adequate scheme, such as Bayesian inversion (Mosegaard \& Tarantola 1995) — which is already commonly adopted in multi-observable lithospheric modelling (e.g Mather et al. 2018) — and by including other temperature-dependent constraints, such as the effective elastic thickness (Burov \& Diament 1995).

\section{ACKNOWLEDGEMENTS}

We acknowledge and thank all the producers of data cited in this work. Financial support to author AP was provided by Region Friuli Venezia Giulia (Italy) through an European Social Fund 50\% cofunded fellowship (HEaD FP1687011001). We would like to thank Dr Magdala Tesauro for an inspiring discussion on preliminary thermal modelling results. We are sincerely grateful to Dr Derrick Hasterok and an anonymous reviewer for their constructive comments, which were of great help in improving the manuscript. The maps were drawn with the Generic Mapping Tools (GMT) (Wessel et al. 2013) and the GMT/Matlab toolbox (Wessel \& Luis 2017).

Author contribution: AP developed the thermal solver, devised the adopted method, and drafted the manuscript. CB designed the study and helped to draft the manuscript. Both authors contributed to the interpretation and discussion of the results. Both authors read and approved the final manuscript.

Data availability: The data sets are available at doi:10.5281/ze nodo.3358902.

\section{REFERENCES}

Afonso, J.C., Fernàndez, M., Ranalli, G., Griffin, W.L. \& Connolly, J.A.D., 2008. Integrated geophysical-petrological modeling of the lithosphere and sublithospheric upper mantle: methodology and applications, Geochem. Geophys. Geosyst., 9(5), 1-36.

Afonso, J.C., Fullea, J., Griffin, W.L., Yang, Y., Jones, A.G., Yang, Y., Connolly, J.A.D. \& Reilly, S.Y.O., 2013. 3-d multiobservable probabilistic inversion for the compositional andthermal structure of the lithosphere and upper mantle. I: a priori petrological information and geophysical observables, J. geophys. Res.: Solid Earth, 118(5), 2586-2617.

Alessio, K.L., Hand, M., Kelsey, D.E., Williams, M.A., Morrissey, L.J. \& Barovich, K., 2018. Conservation of deep crustal heat production, Geology, 46(4), 2-5.

Allen, P.A. \& Allen, J.R., 2013. Basin Analysis: Principles and Application to Petroleum Play Assessment, John Wiley \& Sons.

Artemieva, I.M. \& Thybo, H., 2013. EUNAseis: a seismic model for Moho and crustal structure in Europe, Greenland, and the North Atlantic region, Tectonophysics, 609, 97-153.

Artemieva, I.M., Thybo, H., Jakobsen, K., Sørensen, N.K. \& Nielsen, L.S., 2017. Heat production in granitic rocks: global analysis based on a new data compilation GRANITE2017, Earth-Sci. Rev., 172, 1-26.

Bouman, J. et al., 2015. GOCE gravity gradient data for lithospheric modeling, Int. J. Appl. Earth Obser. Geoinform., 35(Part A), 16-30.

Braitenberg, C., Wienecke, S., Ebbing, J., Born, W. \& Redfield, T., 2007. Joint gravity and isostatic analysis for basement studies-a novel tool, in Proceedings of the EGM 2007 International Workshop, At Capri, Italy.

Braitenberg, C., Mariani, P. \& Pivetta, T., 2011. GOCE observations in exploration geophysics, in Proceedings of the 4th International GOCE User Workshop, ESA SP-696, Munich, Germany, 31 March-01 April 2011.

Brockmann, J.M., Zehentner, N., Höck, E., Pail, R., Loth, I., Mayer-Gürr, T. \& Schuh, W.-D., 2014. EGM_TIM_RL05: an independent geoid with centimeter accuracy purely based on the GOCE mission, Geophys. Res. Lett., 41(22), 8089-8099.

Bucha, B. \& Janák, J., 2013. A MATLAB-based graphical user interface program for computing functionals of the geopotential up to ultra-high degrees and orders, Comput. Geosci., 56, 186-196.

Burov, E.B. \& Diament, M., 1995. The effective elastic thickness (Te) of continental lithosphere: what does it really mean? J. geophys. Res.: Solid Earth, 100(B3), 3905-3927.

Cammarano, F., Tackley, P. \& Boschi, L., 2011. Seismic, petrological and geodynamical constraints on thermal and compositional structure of the upper mantle: global thermochemical models, J. geophys. Int., 187(3), $1301-1318$

Čermák, V., 1993. Lithospheric thermal regimes in Europe, Phys. Earth planet. Inter., 79(1-2), 179-193.

Čermák, V. \& Bodri, L., 1986. Two-dimensional temperature modelling along five East-European geotraverses, J. Geodyn., 5(2), 133-163.

Chapman, D.S., 1986. Thermal gradients in the continental crust, Geol. Soc., Lond., Spec. Publ., 24(1), 63-70.

Chen, W., Tenzer, R. \& Gu, X., 2014. Sediment stripping correction to marine gravity data, Mar. Geod., 37(4), 419-439.

Davies, J.H. \& Davies, D.R., 2010. Earth's surface heat flux, Solid Earth, 1(1), 5-24.

Davis, T., 2006. Direct Methods for Sparse Linear Systems, Society for Industrial and Applied Mathematics, doi:10.1137/1.9780898718881.

Driscoll, J.R. \& Healy, D.M., 1994. Computing fourier transforms and convolutions on the 2-sphere, Adv. Appl. Math., 15(2), 202-250.

Eaton, D.W., Darbyshire, F., Evans, R.L., Grütter, H., Jones, A.G. \& Yuan, X., 2009. The elusive lithosphere-asthenosphere boundary (LAB) beneath cratons, Lithos, 109(1-2), 1-22.

Ebbing, J., Braitenberg, C. \& Götze, H., 2001. Forward and inverse modelling of gravity revealing insight into crustal structures of the Eastern Alps, Tectonophysics, 337(3-4), 191-208.

Fischer, K.M., Ford, H.A., Abt, D.L. \& Rychert, C.A., 2010. The lithosphere-asthenosphere boundary, Ann. Rev. Earth planet. Sci., 38(1), $551-575$.

Floberghagen, R., Fehringer, M., Lamarre, D., Muzi, D., Frommknecht, B., Steiger, C., Piñeiro, J. \& da Costa, A., 2011. Mission design, operation and exploitation of the gravity field and steady-state ocean circulation explorer mission, J. Geod., 85(11), 749-758.

Geissler, W.H., Sodoudi, F. \& Kind, R., 2010. Thickness of the central and eastern European lithosphere as seen by $\mathrm{S}$ receiver functions, J. geophys. Int., 181(2), 604-634.

GOCE-ESA, 2014. GO CONS GCF 2 TIM R5 datasheet. 
Gosnold, W.D., 2011. Global heat flow database, Provided by the University of North Dakota, interim custodian. https://engineering.und.edu/research /global-heat-flow-database/.

Grad, M. \& Tiira, T., ESC Working Group, 2009. The Moho depth map of the European Plate, J. geophys. Int., 176(1), 279-292.

Griffin, W.L., O'Reilly, S.Y., Afonso, J.C. \& Begg, G.C., 2009. The composition and evolution of lithospheric mantle: a re-evaluation and its tectonic implications, J. Petrol., 50(7), 1185-1204.

Grombein, T., Seitz, K. \& Heck, B., 2016. The rock-water-ice topographic gravity field model RWI_TOPO_2015 and its comparison to a conventional rock-equivalent version, Surv. Geophys., 37(5), 937-976.

Guerri, M., Cammarano, F. \& Connolly, J.A.D., 2015. Effects of chemical composition, water and temperature on physical properties of continental crust: composition effects on crust properties, Geochem. Geophys. Geosyst., 16(7), 2431-2449.

Hasterok, D. \& Chapman, D.D.S., 2011. Heat production and geotherms for the continental lithosphere, Earth planet. Sci. Lett., 307(1-2), 59-70.

Hasterok, D. \& Gard, M., 2016. Utilizing thermal isostasy to estimate sublithospheric heat flow and anomalous crustal radioactivity, Earth planet. Sci. Lett., 450, 197-207.

Hasterok, D. \& Webb, J., 2017. On the radiogenic heat production of igneous rocks, Geosci. Front., 8(5), 919-940.

, Hasterok, D., Gard, M. \& Webb, J., 2017. On the radiogenic heat production of metamorphic, igneous, and sedimentary rocks, Geosci. Front., 9, (6), 1777-1794.

Hauck, S.A., Phillips, R.J. \& Hofmeister, A.M., 1999. Variable conductivity: effects on the thermal structure of subducting slabs, Geophys. Res. Lett., 26(21), 3257-3260.

Hayford, J.F. \& Bowie, W., 1912. The effect of topography and isostatic compensation upon the intensity of gravity, US Department of Commerce Special Publication, 10, doi:10.2307/199909.

Hinze, W.J., 2003. Bouguer reduction density, why 2.67? Geophysics, 68(5), 1559-1560.

Hirt, C. \& Kuhn, M., 2014. Band-limited topographic mass distribution generates full-spectrum gravity field: gravity forward modeling in the spectral and spatial domains revisited, J. geophys. Res.: Solid Earth, 119(4), 3646-3661.

Hirt, C. \& Rexer, M., 2015. Earth2014: 1 arc-min shape, topography, bedrock and ice-sheet models - available as gridded data and degree-10,800 spherical harmonics, Int. J. Appl. Earth Obser. Geoinform., 39, 103-112.

Hofmann-Wellenhof, B. \& Moritz, H., 2006. Physical Geodesy, Springer Science \& Business Media, doi:10.1007/978-3-211-33545-1.

Hofmeister, A.M., 1999. Mantle values of thermal conductivity and the geotherm from phonon lifetimes, Science, 283(5408), 1699-1706.

Horváth, F. et al., 2015. Evolution of the Pannonian basin and its geothermal resources, Geothermics, 53, 328-352.

Huang, Y., Chubakov, V., Mantovani, F., Rudnick, R.L. \& McDonough, W.F., 2013. A reference Earth model for the heat-producing elements and associated geoneutrino flux, Geochem. Geophys. Geosyst., 14(6), 20032029.

Jaupart, C. \& Mareschal, J.-C., 2003. Constraints on crustal heat production from heat flow data, in Treatise on Geochemistry, pp. 65-84, eds Holland, H.D. \& Turekian, K.K., Pergamon.

Jaupart, C., Mareschal, J.C. \& Iarotsky, L., 2016. Radiogenic heat production in the continental crust, Lithos, 262, 398-427.

Jokinen, J. \& Kukkonen, I.T., 1999. Random modelling of the lithospheric thermal regime: forward simulations applied in uncertainty analysis, Tectonophysics, 306(3-4), 277-292.

Jones, A.G., Plomerova, J., Korja, T., Sodoudi, F. \& Spakman, W., 2010. Europe from the bottom up: a statistical examination of the central and northern European lithosphere-asthenosphere boundary from comparing seismological and electromagnetic observations, Lithos, 120(1-2), 14-29.

Kaban, M.K., Schwintzer, P. \& Reigber, C., 2004. A new isostatic model of the lithosphere and gravity field, J. Geod., 78(6), 368-385.

Kaban, M.K., Tesauro, M. \& Cloetingh, S., 2010. An integrated gravity model for Europe's crust and upper mantle, Earth planet. Sci. Lett., 296(34), 195-209.
Kuhn, M. \& Featherstone, W.E., 2005. Construction of a synthetic earth gravity model by forward gravity modelling, Window Future Geod., 128, 350-355.

Lee, W.H. \& Uyeda, S., 1965. Review of heat flow data, in Terrestrial Heat Flow, Vol. 8, pp. 87-190, American Geophysical Union.

Majorowicz, J. \& Wybraniec, S., 2011. New terrestrial heat flow map of Europe after regional paleoclimatic correction application, Int. J. Earth Sci., 100(4), 881-887.

Mareschal, J.-C. \& Jaupart, C., 2013. Radiogenic heat production, thermal regime and evolution of continental crust, Tectonophysics, 609, 524-534.

Mariani, P., Braitenberg, C. \& Ussami, N., 2013. Explaining the thick crust in Paraná basin, Brazil, with satellite GOCE gravity observations, J. South Am. Earth Sci., 45, 209-223.

Mather, B., McLaren, S., Taylor, D., Roy, S. \& Moresi, L., 2018. Variations and controls on crustal thermal regimes in southeastern australia, Tectonophysics, 723, 261-276.

Mazur, S., Mikolajczak, M., Krzywiec, P., Malinowski, M., Lewandowski, M. \& Buffenmyer, V., 2016. Pomeranian Caledonides, NW Poland - a collisional suture or thin-skinned fold-and-thrust belt? Tectonophysics, 692, 29-43.

Montagner, J.-P. \& Anderson, D.L., 1989. Constrained reference mantle model, Phys. Earth planet. Inter., 58(2-3), 205-227.

Mosegaard, K. \& Tarantola, A., 1995. Monte Carlo sampling of solutions to inverse problems, J. geophys. Res.: Solid Earth, 100(B7), 12431-12447.

Oldenburg, D.W., 1974. The inversion and interpretation of gravity anomalies, Geophysics, 39(4), 526-536.

O'Reilly, S.Y. \& Griffin, W.L., 2013. Moho vs crust-mantle boundary: evolution of an idea, Tectonophysics, 609, 535-546.

Pail, R. et al., 2011. First goce gravity field models derived by three different approaches, J. Geod., 85(11), 819, doi:10.1007/s00190-011-0467-x.

Pasyanos, M.E., Masters, T.G., Laske, G. \& Ma, Z., 2014. LITHO1.0: an updated crust and lithospheric model of the earth, J. geophys. Res.: Solid Earth, 119(3), 2153-2173.

Plomerová, J. \& Babuška, V., 2010. Long memory of mantle lithosphere fabric-European lab constrained from seismic anisotropy, Lithos, 120(1), 131-143.

Pollack, H.N., Hurter, S.J. \& Johnson, J.R., 1993. Heat flow from the earth's interior: analysis of the global data set, Rev. Geophys., 31(3), 267-280.

Priestley, K. \& McKenzie, D., 2006. The thermal structure of the lithosphere from shear wave velocities, Earth planet. Sci. Lett., 244(1-2), 285-301.

Przybycin, A.M., Scheck-Wenderoth, M. \& Schneider, M., 2015. The 3D conductive thermal field of the North Alpine Foreland Basin: influence of the deep structure and the adjacent European Alps, Geotherma. Ener., 3(1), 17, doi:10.1186/s40517-015-0038-0.

Reguzzoni, M. \& Sampietro, D., 2015. GEMMA: an Earth crustal model based on GOCE satellite data, Int. J. Appl. Earth Obser. Geoinform., 35, $31-43$.

Revil, A., 2000. Thermal conductivity of unconsolidated sediments with geophysical applications, J. geophys. Res.: Solid Earth, 105(B7), 1674916768.

Rexer, M., Hirt, C., Claessens, S. \& Tenzer, R., 2016. Layer-based modelling of the earth's gravitational potential up to $10-\mathrm{km}$ scale in spherical harmonics in spherical and ellipsoidal approximation, Surv. Geophys., 37(6), 1035-1074.

Schön, J., 2011. Physical Properties of Rocks: A Workbook. Handbook of Petroleum Exploration and Production, Elsevier Science.

Sebera, J., Haagmans, R., Floberghagen, R. \& Ebbing, J., 2018. Gravity spectra from the density distribution of Earth's uppermost $435 \mathrm{~km}$, Surv. Geophys., 39(2), 227-244.

Sibson, R., 1981. A brief description of natural neighbor interpolation, in Interpreting Multivariate Data, pp. 21-36, ed. ,Barnet, V., Wiley.

Simmons, N.A., Forte, A.M., Boschi, L. \& Grand, S.P., 2010. GyPSuM: a joint tomographic model of mantle density and seismic wave speeds, $J$. geophys. Res.: Solid Earth, 115(12), 1-24.

Sjöberg, L. \& Bagherbandi, M., 2011. A method of estimating the Moho density contrast with a tentative application of EGM08 and CRUST2.0, Acta Geophys., 59, 502-525. 
Smith, G., 1985. Numerical Solution of Partial Differential Equations: Finite Difference Methods, Oxford Applied Mathematics, Clarendon Press.

Starostenko, V. et al., 2018. Lithospheric structure along wide-angle seismic profile GEORIFT 2013 in Pripyat-Dnieper-Donets Basin (Belarus and Ukraine), J. geophys. Int., 212(3), 1932-1962.

Steinberger, B. \& Becker, T.W., 2016. A comparison of lithospheric thickness models, Tectonophysics, 746, 325-338.

Stüwe, K., 2007. Geodynamics of the Lithosphere, Springer Science.

Szwillus, W., Ebbing, J. \& Holzrichter, N., 2016. Importance of far-field topographic and isostatic corrections for regional density modelling, $J$. geophys. Int., 207(1), 274-287.

Tenzer, R.,Hamayun, Novák, P., Gladkikh, V. \& Vajda, P., 2012. Global crust-mantle density contrast estimated from EGM2008, DTM2008, CRUST2.0, and ICE-5G, Pure appl. Geophys., 169(9), 1663-1678.

Tesauro, M., Kaban, M.K. \& Cloetingh, S.A. P.L., 2008. Eucrust-07: a new reference model for the european crust, Geophys. Res. Lett., 35(5), doi:10.1029/2007GL032244.

Tesauro, M., Kaban, M.K. \& Cloetingh, S.A., 2009. A new thermal and rheological model of the european lithosphere, Tectonophysics, 476(34), 478-495.

Tărăpoancă, M., Bertotti, G., Maţenco, L., Dinu, C. \& Cloetingh, S. A. P.L., 2003. Architecture of the Focşani depression: a $13 \mathrm{~km}$ deep basin in the Carpathians bend zone (Romania), Tectonics, 22(6), doi: $10.1029 / 2002 \mathrm{TC} 001486$.

Uieda, L., 2017. Tesseroids v1.2.1: forward modeling of gravitational fields in spherical coordinates, doi:10.5281/zenodo.582366.

Uieda, L., Barbosa, V. \& Braitenberg, C., 2016. Tesseroids: forwardmodeling gravitational fields in spherical coordinates, Geophysics, 81, (5), F41-F48, doi:10.1190/geo2015-0204.1.

van der Meijde, M., Pail, R., Bingham, R. \& Floberghagen, R., 2015. GOCE data, models, and applications: a review, Int. J. Appl. Earth Obser. Geoinform., 35(Part A), 4-15.

Vilà, M., Fernández, M. \& Jiménez-Munt, I., 2010. Radiogenic heat production variability of some common lithological groups and its significance to lithospheric thermal modeling, Tectonophysics, 490(3-4), 152-164, doi:10.1016/j.tecto.2010.05.003.

Wedepohl, K.H., 1995. The composition of the continental crust, Geochim. Cosmochim. Acta, 59(7), 1217-1232.

Wessel, P., 2009. A general-purpose Green's function-based interpolator, Comput. Geosci., 35(6), 1247-1254.

Wessel, P. \& Luis, J.F., 2017. The GMT/MATLAB toolbox, Geochem. Geophys. Geosyst., 18(2), 811-823.

Wessel, P., Smith, W. H.F., Scharroo, R., Luis, J. \& Wobbe, F., 2013. Generic mapping tools: improved version released, EOS, Trans. Am. Geophys. Un., 94(45), 409-410.

Wieczorek, M., Meschede, M., Sales de Andrade, E., Oshchepkov, I., Xu, B. \& Walker, A., 2018. SHTOOLS: version 4.3, doi:10.5281/zenodo.1346663.

Woodside, W. \& Messmer, J., 1961. Thermal conductivity of porous media, J. Appl. Phys., 32(9), 1688-1699.

Xu, Y., Shankland, T.J., Linhardt, S., Rubie, D.C., Langenhorst, F. \& Klasinski, K., 2004. Thermal diffusivity and conductivity of olivine, wadsleyite and ringwoodite to $20 \mathrm{GPa}$ and $1373 \mathrm{~K}$, Phys. Earth planet. Inter., 143(12), 321-336.

Yegorova, T.P. \& Pavlenkova, G.A., 2015. Velocity-density models of the Earth's crust and upper mantle from the quartz, Craton, and Kimberlite superlong seismic profiles, Izvestiya, Phys. Solid Earth, 51(2), 250-267.

\section{SUPPORTING INFORMATION}

Supplementary data are available at $G J I$ online.

\section{PaBr2019_SupplMat.pdf}

Please note: Oxford University Press is not responsible for the content or functionality of any supporting materials supplied by the authors. Any queries (other than missing material) should be directed to the corresponding author for the paper. 